\title{
Quantification of Carbon Nanotubes in Environmental Matrices: Current Capabilities, Case Studies, and Future Prospects
}

\author{
Elijah J. Petersen, ${ }^{*}{ }^{\dagger}$ D. Xanat Flores-Cervantes, ${ }^{\ddagger}, \nabla$ Thomas D. Bucheli, ${ }^{\S}$ Lindsay C. C. Elliott, ${ }^{\dagger}$
} Jeffrey A. Fagan, ${ }^{\dagger}$ Alexander Gogos, ${ }^{\ddagger}, \S$ Shannon Hanna, ${ }^{\dagger}$ Ralf Kägi, ${ }^{\ddagger}$ Elisabeth Mansfield, ${ }^{\dagger}$ Antonio R. Montoro Bustos, ${ }^{\dagger}$ Desiree L. Plata, ${ }^{\prime \prime}$ Vytas Reipa, $^{\dagger}$ Paul Westerhoff, ${ }^{\perp}$ and Michael R. Winchester ${ }^{\dagger}$

\begin{abstract}
${ }^{\dagger}$ Material Measurement Laboratory, National Institute of Standards and Technology, Gaithersburg, Maryland 20899, United States ${ }^{\ddagger}$ Eawag, Swiss Federal Institute of Aquatic Science and Technology, Überlandstrasse 133, CH-8600 Dübendorf, Switzerland

${ }^{\S}$ Agroscope, Institute of Sustainability Sciences ISS, 8046 Zurich, Switzerland

"Department of Chemical and Environmental Engineering, Yale University, New Haven, Connecticut 06520, United States

${ }^{\perp}$ School of Sustainable Engineering and The Built Environment, Arizona State University, Box 3005, Tempe, Arizona 85278-3005, United States
\end{abstract}

\section{Supporting Information}

ABSTRACT: Carbon nanotubes (CNTs) have numerous exciting potential applications and some that have reached commercialization. As such, quantitative measurements of CNTs in key environmental matrices (water, soil, sediment, and biological tissues) are needed to address concerns about their potential environmental and human health risks and to inform application development. However, standard methods for CNT quantification are not yet available. We systematically and critically review each component of the current methods for CNT quantification including CNT extraction approaches, potential biases, limits of detection, and potential for standardization. This review reveals that many of the

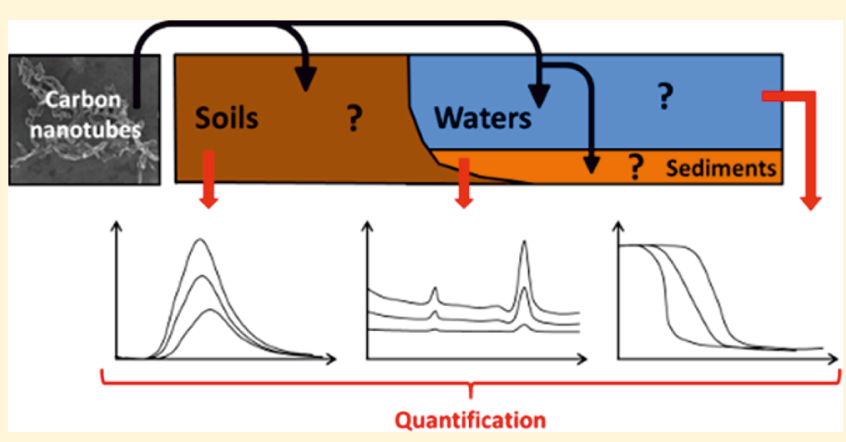
techniques with the lowest detection limits require uncommon equipment or expertise, and thus, they are not frequently accessible. Additionally, changes to the CNTs (e.g., agglomeration) after environmental release and matrix effects can cause biases for many of the techniques, and biasing factors vary among the techniques. Five case studies are provided to illustrate how to use this information to inform responses to real-world scenarios such as monitoring potential CNT discharge into a river or ecotoxicity testing by a testing laboratory. Overall, substantial progress has been made in improving CNT quantification during the past ten years, but additional work is needed for standardization, development of extraction techniques from complex matrices, and multimethod comparisons of standard samples to reveal the comparability of techniques.

\section{INTRODUCTION}

The steady increase in potential applications ${ }^{1}$ and production $^{1,2}$ of carbon nanotubes (CNTs) and their inevitable release during the life cycle of products has raised questions regarding their potential impact on humans and the environment., CNTs can be conceptually understood as rolled up graphitic sheets of hexagonally arranged carbon atoms with $s p^{2}$ hybridization. These materials have exceptional mechanical strength as well as thermal and electrical conductivity properties that make them ideal for a myriad of potential applications (e.g., construction, environmental, optical, electronic, and biomedical). ${ }^{5-8}$ The annual production capacity of CNTs reached $2 \times 10^{6} \mathrm{~kg}$ (2.25 ktons) $\mathrm{yr}^{-1}$ in 2011 with an estimated production capacity of $5 \times 10^{6} \mathrm{~kg}$ (4.5 ktons) $\mathrm{yr}^{-1}$; this change was a 10 -fold increase since $2006 .{ }^{1}$ With increasing production volume, it is important to determine the potential for biological exposures to CNT during the production, usage, and disposal of CNT-enabled products. The necessary linchpin to quantifying potential CNT exposure, and any risks from it, is the availability of robust analytical methods for quantifying CNTs in complex environmental matrices. ${ }^{9}$ These methods are critical for the assessment of potential CNT exposure, toxicity testing on the potential risks that may occur after exposure, and determination of the environmental fate of CNTs. ${ }^{10}$

Analytical techniques to quantify CNTs usually rely on unique physicochemical properties of CNTs that differentiate them from other compounds in relevant media. These

Received: November 27, 2015

Revised: $\quad$ March 4, 2016

Accepted: April 6, 2016

Published: April 6, 2016 

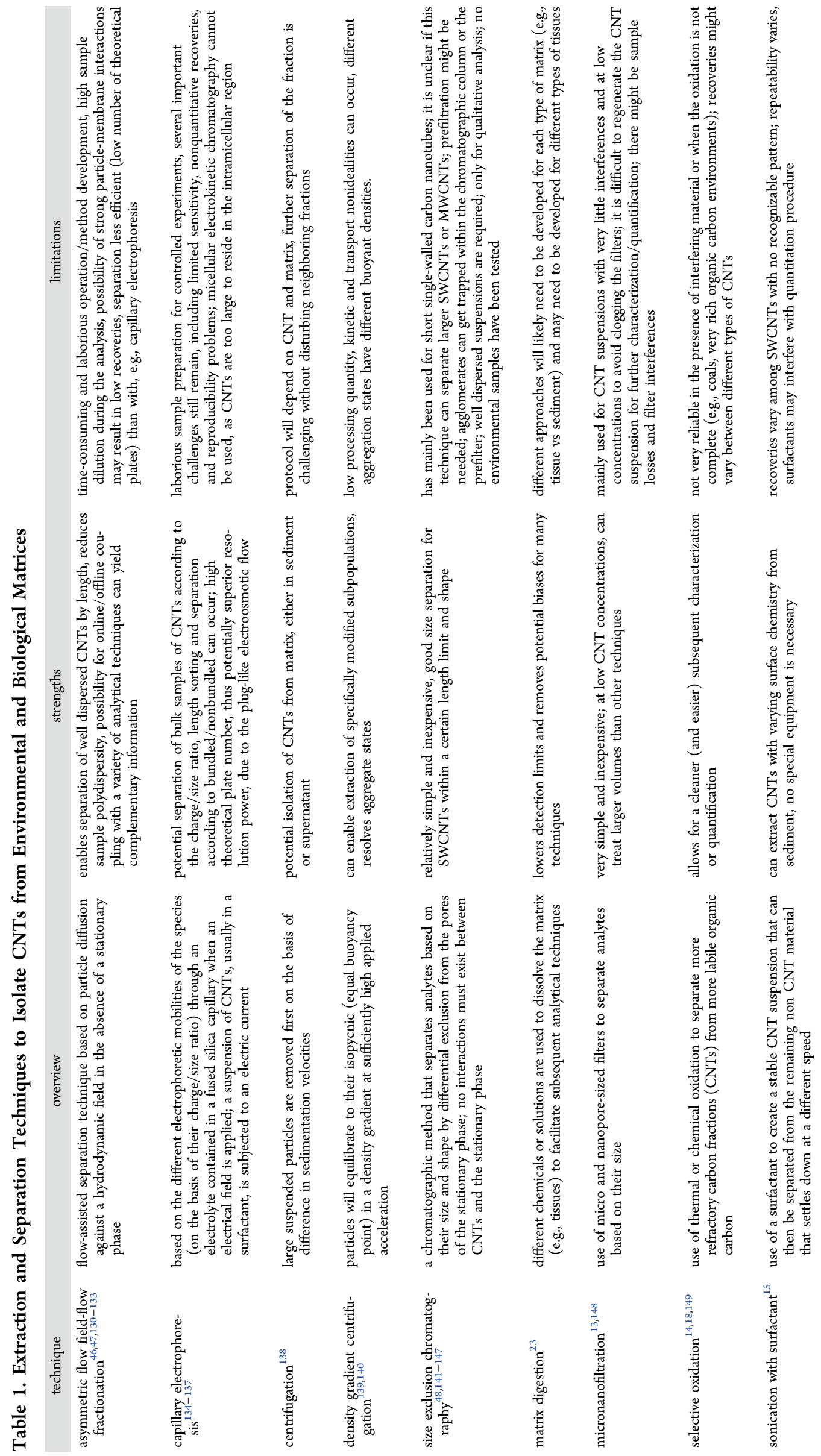
approaches leverage the structural, thermal, and electrical properties of CNTs and include spectroscopic, ${ }^{11-15}$ optical, ${ }^{16,17}$ and thermal ${ }^{16,14,18}$ techniques used individually or in combination. ${ }^{9,15}$ Importantly, techniques used for analysis of traditional organic and inorganic toxic chemicals are often not applicable for the following reasons: (a) unlike most organic pollutants, CNTs have a distribution of lengths and diameters rather than a single molecular structure and, therefore, mass spectrometry methods, a key tool in current organic analytical methods, generally cannot be used; the large molecular weight of CNTs could potentially challenge mass spectrometric methods too; (b) most techniques cannot distinguish between CNTs and naturally occurring black carbon allotropes (e.g., soot or charcoal), which are present at much higher concentrations in the environment than those modeled for $\mathrm{CNTs}^{19}$ (c) several other carbon forms are often present in samples (e.g., natural organic matter; NOM) which may interfere with CNT quantification in the sample matrix; and (d) the wide range of shapes, sizes, diameters, functional groups, and agglomeration states make it difficult to develop a universal analytical method for quantifying all types of CNTs. In addition, commercially manufactured CNTs may also contain substantial concentrations of metal catalysts, amorphous carbon, and graphitic (non-CNT) nanoparticles (NPs) which may cause biases with some analytical techniques, but are essential for other techniques. ${ }^{20-22}$

While there have been numerous analytical techniques used to quantify CNTs in various matrices, ${ }^{4,14-16,23-38}$ for each technique there have only been a limited number of studies, often made by a single laboratory, and thus the robustness of the methods is unknown. In particular, relevant experimental parameters including comprehensive characterization of the CNTs and quantities used for testing and calibration procedures are not always reported. Moreover, failed attempts to apply new methods and techniques or to replicate approaches described in previous studies are often not published, and thus, the limitations of each technique such as potential biases for various matrices (e.g., water or soil with natural (NOM) or soil organic matter (SOM)) are often unclear. Overall, while some recent review papers have focused in part on CNT quantification, ${ }^{4,39,40}$ many critical topics (e.g., interferences in key matrices (environmental, biological, synthetic polymers), and the potential biases with CNT quantification from changes to the CNTs (e.g., oxidation)) related to the development of robust, precise, and reproducible CNT quantification methods have not yet been critically evaluated.

This manuscript reviews CNT quantification techniques and evaluates their applicability for different key matrices (water, soil/sediment, tissue) and different types of CNTs (i.e., singlewall carbon nanotubes (SWCNTs) or multiwall carbon nanotubes (MWCNTs)). We report a critical evaluation and comparison among the advantages and limitations of each technique including biases for relevant matrices, biases from physicochemical changes to CNTs in those matrices (i.e., oxidation/degradation, wrapping with organic molecules, and agglomeration), detection limits in various matrices, the potential for standardization, and the types of CNTs that can be analyzed. In addition, methods for extraction or separation of CNTs from different matrices, which may be necessary for sample preparation for some techniques, are enumerated. These quantification, separation, and extraction techniques may also be relevant for quantifying CNT loading in consumer products but the focus of this paper will be on scenarios relevant for assessing the potential environmental risks and fate of CNTs. For example, potential quantification techniques for representative scenarios related to environmental release and potential ecotoxicological effects are discussed. Future research topics to elucidate and improve the analytical performance of these techniques and CNT quantification in general are also highlighted. This paper is intended to serve as a reference to guide scientists in the area of CNT quantification through the selection of an appropriate technique given a type of CNT, sample matrix, and CNT concentration. Given the substantial literature on physicochemical properties and characterization of $\mathrm{CNTs},{ }^{41,42}$ basic background information on these subjects is not provided. While CNTs are also widely known to cause artifacts in many nanotoxicology assays such as by adsorbing key reagents, ${ }^{26,43-45}$ this manuscript will focus on biases related to quantification of CNTs and not biases in the measurements of their potential toxicological effects.

\section{EXTRACTION AND SEPARATION PROCEDURES FOR CNTS}

Numerous techniques have been investigated to extract or separate CNTs from different matrices to overcome quantification limits in complex biological and environmental media (Table 1). In this manuscript, we define "extraction" as the isolation of analytes from a matrix by their physical transition from one phase into another. In contrast, separation means the isolation of analytes from themselves (e.g., differently sized CNTs), or from a matrix within a given phase (e.g., a mobile phase in chromatography or field flow fractionation). Successful extraction methods usually involve the suspension of CNTs in a specific media in which interfering compounds are less soluble, but the converse approach can also be utilized: removing the matrix while leaving the CNTs. However, most reported separation or extraction methods have only been used by a single research group in one or a small number of studies to partly or fully separate CNTs from an environmental matrix (e.g., asymmetric flow field flow fractionation (AF4), matrix digestion, and sonication with surfactants)..$^{15,23,46}$ Other techniques have not yet been utilized with environmental and biological matrices (e.g., density gradient centrifugation, gel permeation chromatography, capillary electrophoresis, twopolymer phase extraction), but instead have been successfully applied to simpler matrices (e.g., deionized water) or have been used for CNT purification. ${ }^{4-49}$ These techniques may be valuable for use with environmental and biological matrices and are also listed in Table 1. Conversely, there has been more progress with extraction and analysis of fullerenes, another carbon nanomaterial, from complex matrices. ${ }^{50-56}$

Currently, many challenges remain in CNT extraction and separation strategies. First, it is unclear to what extent many of these techniques would be applicable for both MWCNTs and SWCNTs given the different properties of these two classes of CNTs, as most methods have only been applied to one or the other. This thought may be extended beyond the number of walls, to include any change in physicochemical properties (e.g., length, internal or external diameter, number of walls, or functional groups). Nevertheless, we expect that separation and extraction techniques may have to be tailored for a specific physicochemical property. For example, a method that can isolate short CNTs from a matrix could be ineffective when used against a population of long, highly entangled CNTs. Second, separation or extraction methods have not yet been 


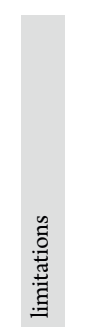

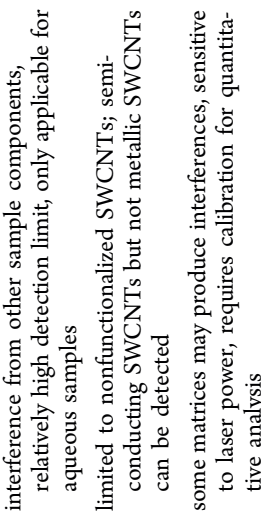

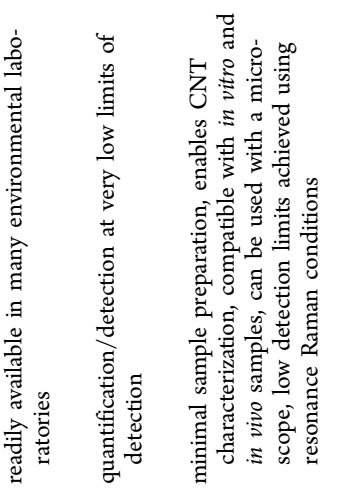

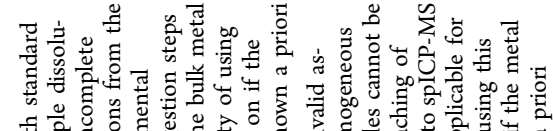

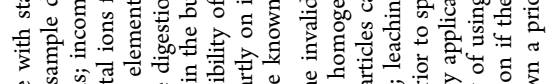

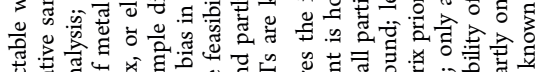

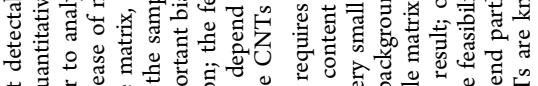

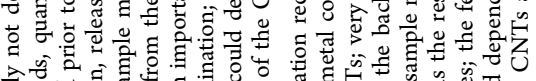

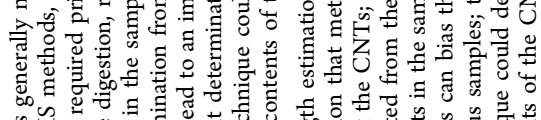

on

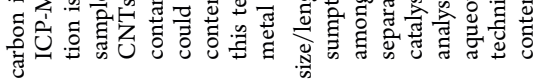
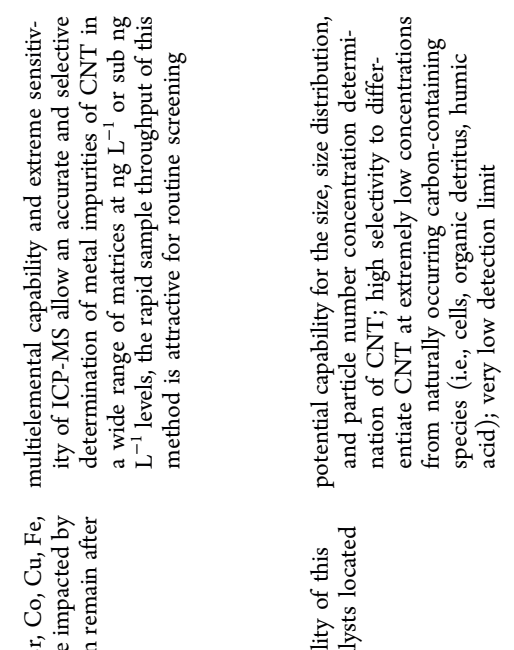

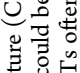

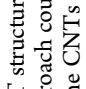

仏言至

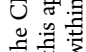

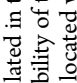

氖

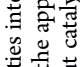

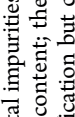

胥它苋

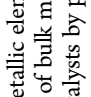

要要

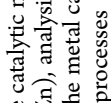

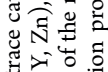

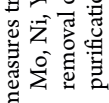

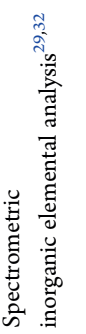

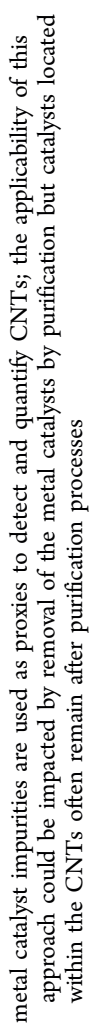

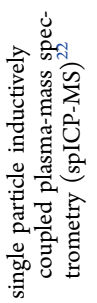
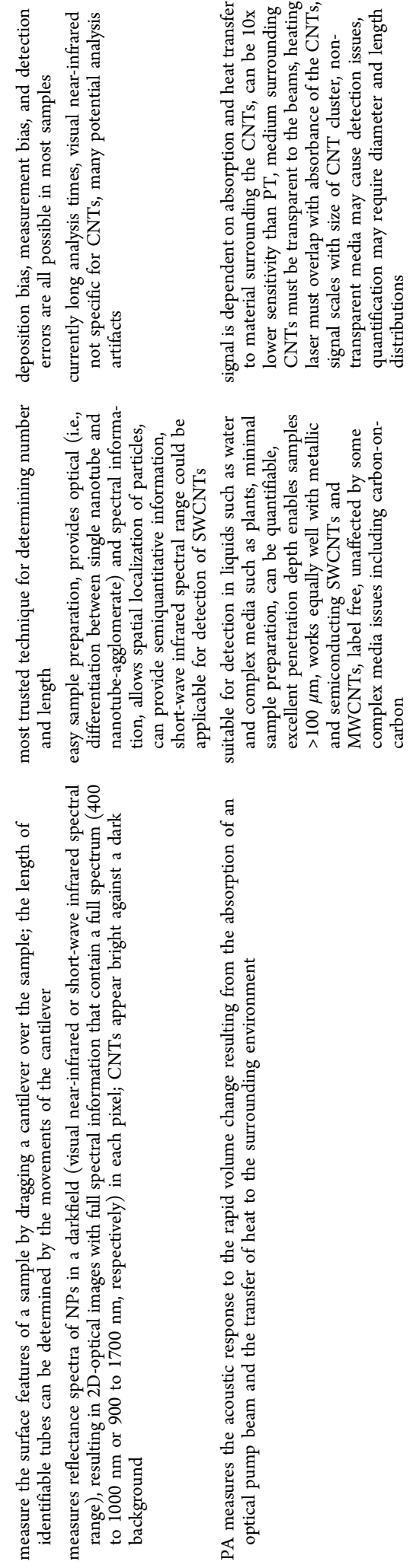

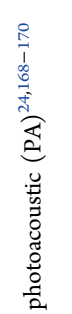




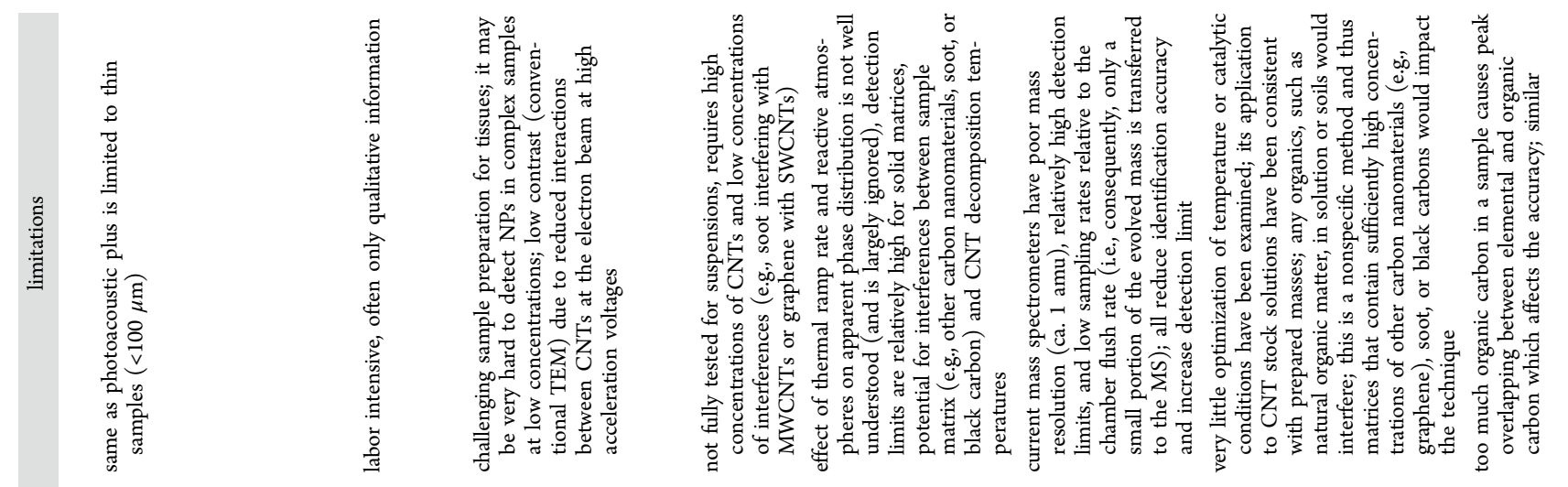

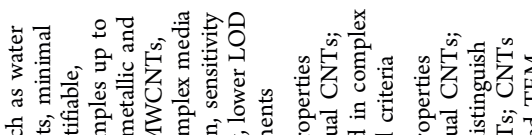

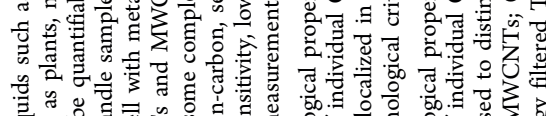

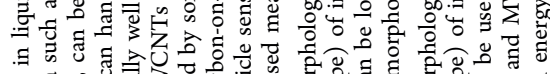

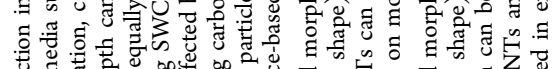

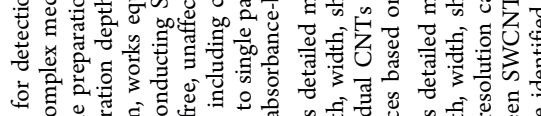

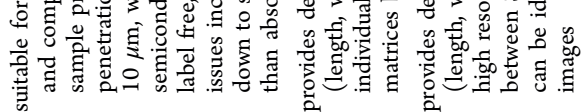
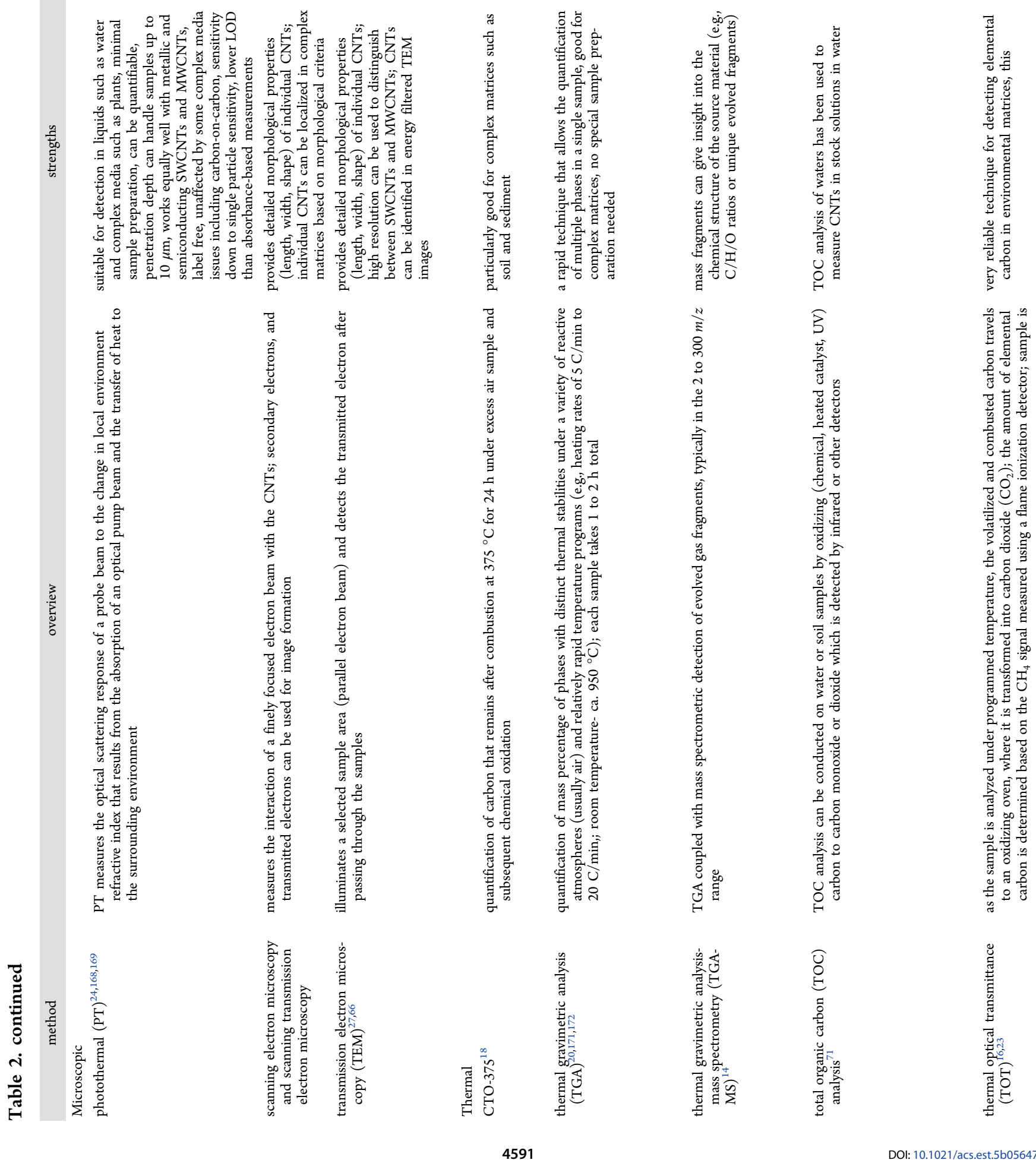

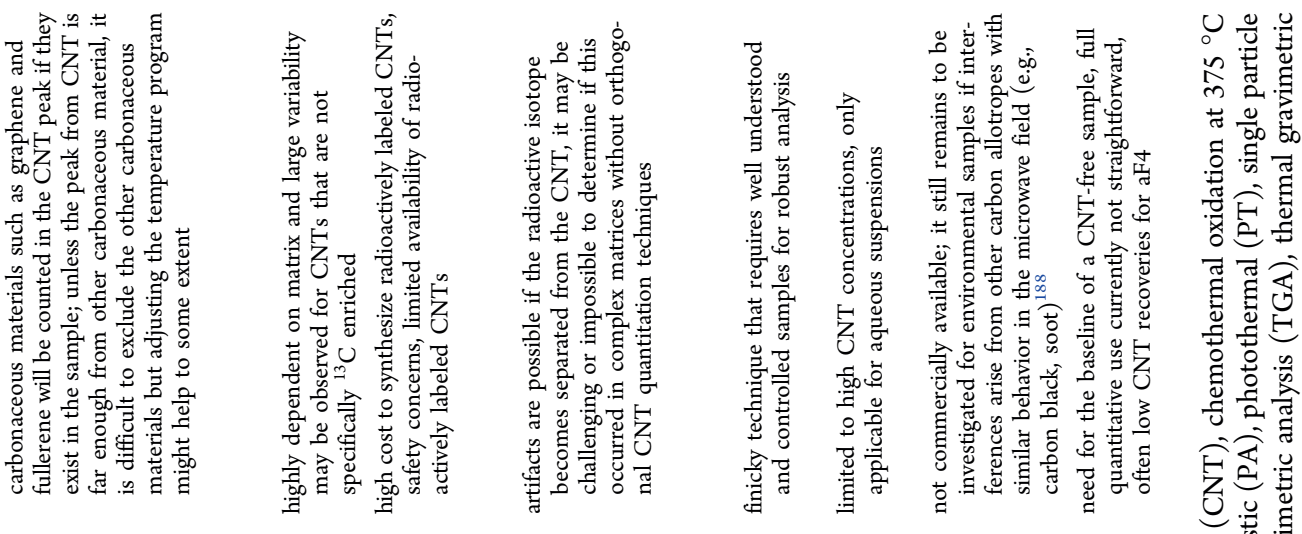

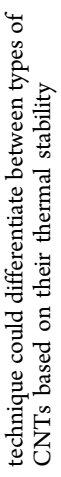
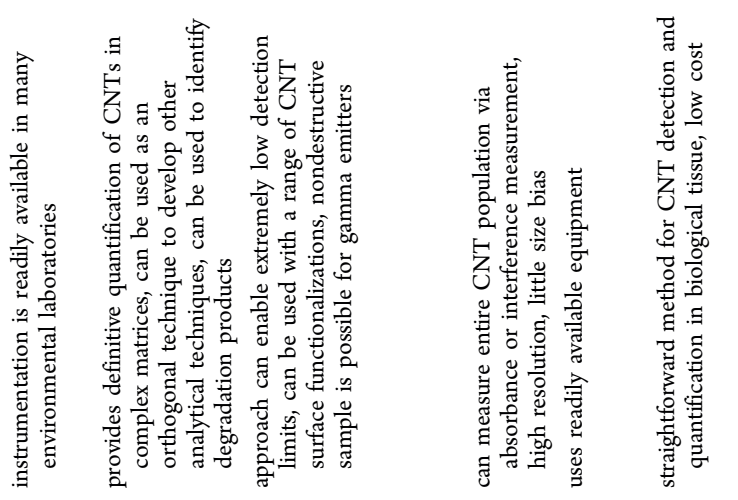

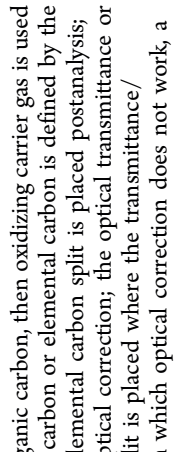

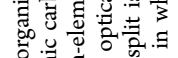

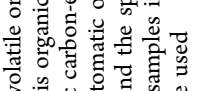

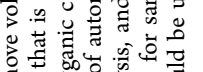

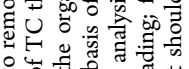

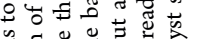

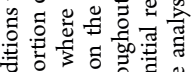

oี

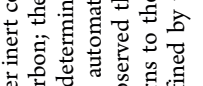

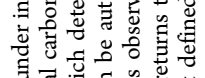

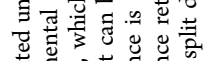

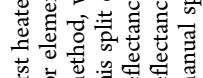
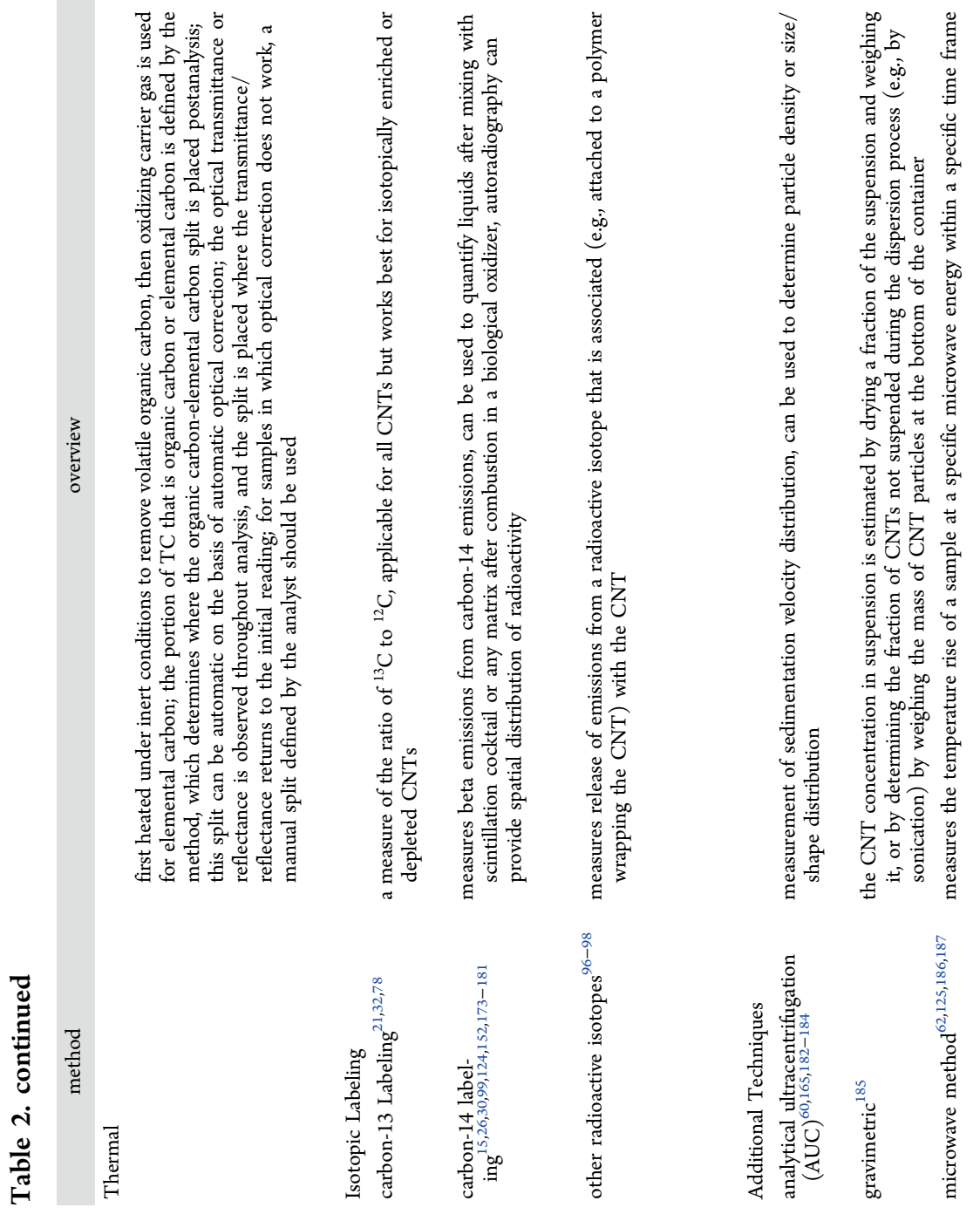

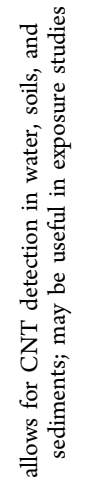

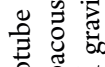

噉

范

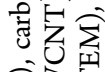

O己

类

总

를 온

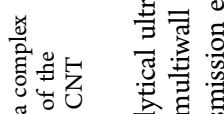

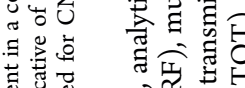

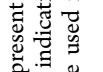

.

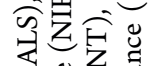

E.

른

小娄声

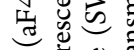

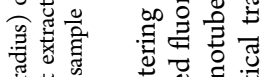

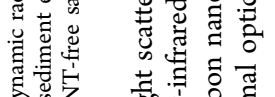

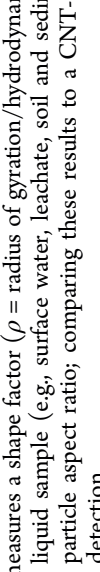

营言 ह

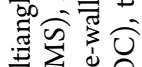

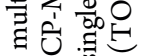

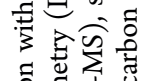

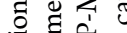

䒕造造

要娄

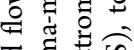

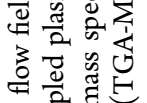

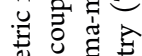

है

安氖

苛声言 के

过范

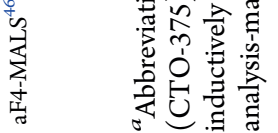




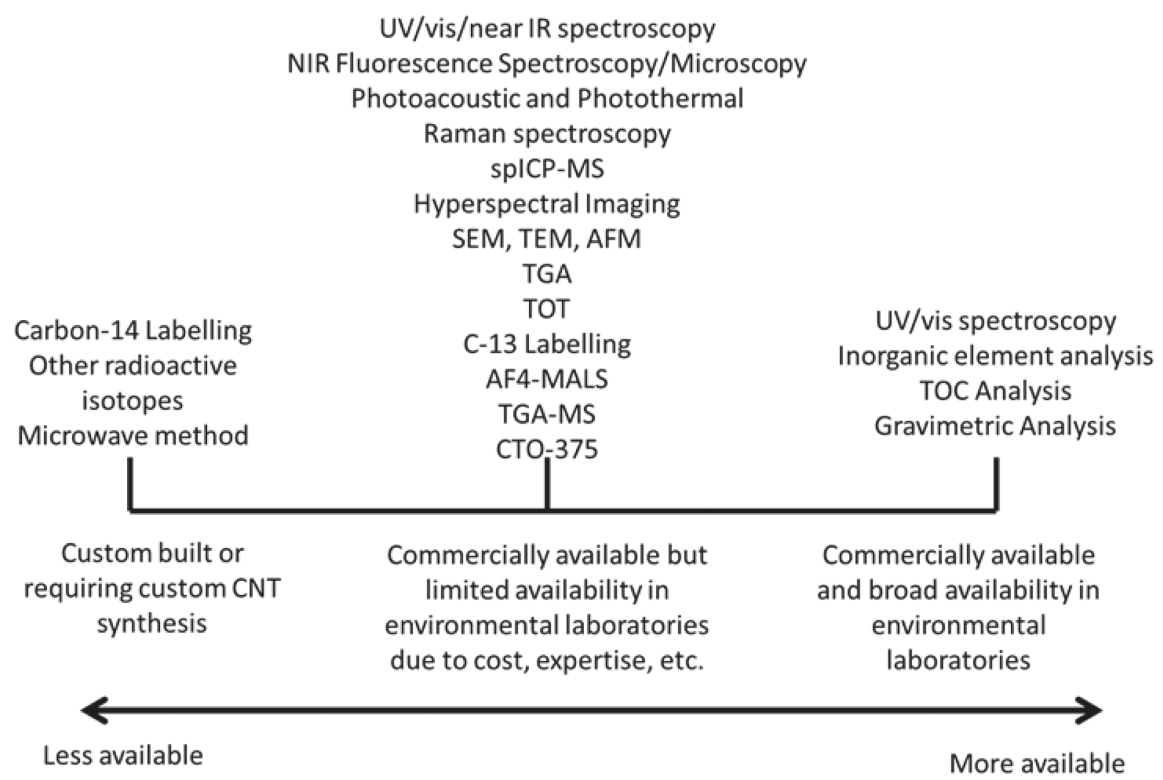

Figure 1. Availability of CNT quantification techniques. Abbreviations: Asymmetric flow field flow fractionation with multiangle light scattering (AF4-MALS), analytical ultracentrifugation (AUC), chemothermal oxidation at $375^{\circ} \mathrm{C}$ (CTO-375), near-infrared fluorescence (NIR), single particle inductively coupled plasma-mass spectrometry (spICP-MS), thermal gravimetric analysis (TGA), thermal gravimetric analysis-mass spectrometry (TGA-MS), total organic carbon (TOC), thermal optical transmittance (TOT), scanning electron microscopy (SEM), transmission electron microscopy (TEM), atomic force microscopy (AFM).

applied to CNTs as utilized in potential consumer applications such as in polymer nanocomposite matrices. Given that CNTs will be released into the environment from consumer products, it is important to quantify the release of CNTs from these products after environmental stresses. It may also be important to quantify the concentration of $\mathrm{CNTs}$ in the consumer products, such as CNT-containing nanocomposites, to determine the potential quantity that could be released. Given challenges related to collecting and quantifying CNTs released from polymeric nanocomposites, one approach to estimate the quantity of CNTs released is to use a mass balance approach by quantifying the CNT concentration in a product before and after environmentally relevant degradation processes. For example, established methods are needed to extract CNTs from CNT-containing nanocomposites before and after the weathering and degradation processes (e.g., due to UV degradation and abrasion) to enable quantification of CNT concentrations. $^{57-60}$ This will allow scientists to more fully address the complete life cycle of nanoenabled consumer products. Finally, extraction or separation procedures may change the physicochemical properties of the CNTs, potentially impacting the reliability of results from analytical methods. One such example is the matrix digestion approach described by Doudrick et al., ${ }^{23}$ which was suitable for subsequent analysis using thermal optical transmittance (TOT), but is potentially unsuitable for spectroscopic quantification by Raman scattering, because of concerns that the Raman spectra (e.g., ratio of D to $\mathrm{G}$ band) may be altered by the digestion procedure. Overall, although encouraging results have been obtained for a limited number of studies, the overall development of extraction and separation methods for CNTs from matrices for quantitative analyses is still a relatively new area of research.

\section{QUANTIFICATION TECHNIQUES}

A broad range of techniques have been developed to quantify or identify CNTs in environmentally and biologically relevant matrices (Table 2). In general, the techniques can be sorted into four groups: those that rely on the unique spectroscopic and thermal characteristics of the CNTs (that enable them to be distinguished from the matrix), those that utilize the presence of metal catalyst impurities (associated with the CNTs from the synthesis process), those that require isotopically enriched or depleted CNTs (e.g., with carbon-14 or carbon13), and finally, microscopic techniques. There are large differences in the sensitivities and applicability of these techniques. Some thermal processes produce detectable gases $\left(\mathrm{CO}, \mathrm{CO}_{2}\right)$, while others measure radiative heating of a sample. For example, the microwave method involved irradiating CNT containing samples with microwave radiation, wherein the carbon nanotubes absorb the microwave radiation, and the increase in temperature is proportional to the CNT concentration for a given matrix. ${ }^{61,62}$ When comparing different studies, even those using the same quantification technique, there is substantial diversity in the characteristics of the CNTs utilized.

It is evident from Figure 1 that, while some instruments used in the CNT quantification techniques are commercially available (e.g., UV/vis/NIR spectroscopy and Raman spectroscopy), most of the techniques require uncommon equipment that need to be partially or wholly custom built (e.g., microwave method, photoacoustic and photothermal imaging) or expertise that is not readily available. The use of uncommon instruments in these techniques also poses challenges for commercial ecotoxicity testing facilities to fulfill guidelines for standard methods related to maintaining a consistent exposure concentration. ${ }^{63}$ While some analytical instruments that can be used to quantify CNTs are widely available (e.g., UV/vis spectrophotometry), some of them have significant potential interferences as will be discussed in detail in subsequent sections. To provide one example, challenges related to the use of UV/vis spectrophotometry have recently been described including absorption coefficients dependent on the CNT 
structure distribution and dispersion method, as well as decreasing absorption coefficients with CNT agglomeration and uncertainty in determining non-CNT from CNT contributions. $^{64,65}$ The lack of robust and widely available analytical methods likely contributes to the exclusive use of nominal concentrations to describe the exposure concentration and the absence of reported changes in CNT concentrations during experiments in many nanoecotoxicology studies.

Microscopic techniques can provide unambiguous identification of the CNTs in a complex matrix (e.g., transmission electron microscopy (TEM) analysis using electron energy loss spectroscopy or high resolution TEM), ${ }^{27,66}$ but low or uneven distributions of CNTs on microscopy samples hamper the conversion of the number of CNTs detected on (several) images to the number/mass concentration of CNTs in a sample. These limitations can be overcome, for matrices without substantial interferences, by using a centrifugationbased method to capture the CNTs from a known volume onto a microscopy sample holder (e.g., TEM grid). Under these conditions, frequency data (number of CNTs per area) can be converted into particle number and mass concentration metrics. ${ }^{67-69}$ However, when one considers projected environmentally relevant concentrations of CNTs (typically ng to $\mu \mathrm{g}$ $\mathrm{kg}^{-1}$ solids), ${ }^{70}$ the likelihood that one captures a CNT onto a microscopy grid with $\mu$ g-sized environmental samples is exceedingly small. Overall, due to limitations related to the sample preparation issues (low CNT concentration especially compared to other solids, overlapping particles, and uneven distribution of CNTs onto the sample holders), results from electron microscopic techniques remain mainly on a qualitative level, and are currently of limited utility for quantitation.

While electron microscopic techniques are very helpful to confirm the identity of CNTs in a matrix if the CNT loading is sufficiently high, reliable controls of the sample matrix without CNTs, the CNTs alone, the sample holder, and any other interferences are needed to avoid false positive or false negative results, but these controls are rarely available for environmental samples. In addition, the amount of time required for sample preparation depends on the samples matrix and greatly varies among techniques. For example, obtaining TEM images suitable for automated image analyses may require that individual CNTs are evenly distributed on a TEM grid and do not overlap with other particles. This often requires elaborate and tailored extraction, dispersion and deposition techniques that are very time intensive to develop. In contrast, sample preparation for hyperspectral imaging microscopy is usually very fast, as liquid samples can be directly cast onto a microscopy slide and subsequently imaged. However, the current commercial setup lacks the possibility for automated image acquisition as well as suitable measures to determine the deposited sample volume, which hampers its quantitative capabilities.

Due to the similarities between CNT structure and that of atmospheric soot or carbon black, many analytical techniques that have been used for their extraction or isolation from air, soil, or sediment have been also used to quantify CNTs (e.g., thermal optical transmittance (TOT), chemothermal oxidation at $375{ }^{\circ} \mathrm{C}$ (CTO-375), thermogravimetric analysis (TGA), and total organic carbon (TOC) $){ }^{14,16,18,71}$ While TOT can measure CNTs, custom temperature ramping programs are required for CNTs that differ from standard National Institute for Occupational Safety and Health (NIOSH) methods used for soot analysis on atmospheric samples. ${ }^{16}$ Similar modifica- tions may also help improve CNT quantification by other thermal techniques such as CTO-375. Sampling of soot in air requires separation from the air, and usually involves filters, impactors or centrifugal separation. Airborne CNTs would likely also be captured by these techniques. ${ }^{72-76}$

All of the quantification techniques are critically assessed in subsequent sections for the potential impact of matrix interferences or interferences from changes that may occur to the CNT in different test systems or the natural environment. For example, the impact of CNT degradation, as has been shown to occur enzymatically and due to interactions with cells and bacteria, ${ }^{77-83}$ and oxidation on the performance of different analytical methods are evaluated. In addition, the limits of detection (LODs) for these techniques in different media are compared and used to assess the potentially relevant techniques for five case study scenarios. The potential for these techniques to be standardized, a critical issue for regulatory agencies, is also discussed.

Evaluation of Potential Matrix Interferences for Quantification Procedures. Perhaps the principal reason that quantification of CNTs in environmentally relevant matrices is challenging is because of matrix interferences, namely difficulties associated with detecting carbon in a carbon background, especially at modeled average environmental CNT concentrations. ${ }^{70,84-86}$ The matrix characteristics that are most likely to cause interferences are described in detail in Supporting Information Table S1. Overall, natural waters and cell media (e.g., in studies with fish or human cells) have significantly fewer matrix interferences compared to biological tissues, soil/sediment, and released material from nanocomposites. For most spectroscopic measurements, while molecules and suspended particles in natural waters and cell media can potentially scatter incoming/outgoing light thus potentially biasing measurements, methods that account for these effects are generally available; in contrast, separation from the matrix is often needed prior to CNT quantification in tissues, soil/sediment, and fragments released from nanocomposites. For inorganic elemental analysis, having a constant and relatively low background metallic content of the matrix of the same element as the catalyst(s) of the CNTs is most important for all relevant matrices to achieve a low LOD and accuracy. Additionally, the multi-isotopic capability of the inorganic elemental analysis may enable qualitative and/or quantitative isotopic analysis when the isotopic ratios of the catalyst particles differ from those typically observed in the environmental matrix. For single-particle inductively coupled plasma-mass spectrometry (spICP-MS) analysis of CNTs, the background metallic content in nanoparticulate form in matrices is similarly important with regards to the accuracy of the measurement, while low background metallic content in dissolved form is necessary for achieving a low LOD. However, spICP-MS instruments operating at microsecond dwell times can only perform nanoparticle isotopic analysis for detection of two elements, a capability which nevertheless can be used to distinguish naturally occurring NPs from their engineered counterparts. $^{87}$ While spICP-time-of-flight (ToF)-MS has recently shown the capacity for multielement analysis, ${ }^{88,89}$ the size limit of detection was larger for gold and silver NPs compared to quadrupole-based instruments. ${ }^{89}$ Given the expected small amounts of the catalysts associated with individual CNTs and challenges associated with determining the background cut off level for SWCNT analysis using spICP- 
$\mathrm{MS}^{22}$ it is unclear if spICP-ToF-MS will work well for CNT quantification.

Thermal techniques often do not show interferences with natural waters and cell media, although there were techniquespecific chemicals in these matrices (e.g., peptone in the media for TGA analysis $)^{90}$ that could impact the results. Two key considerations for many of the thermal techniques are whether components in the matrix can change the thermal stability of the CNTs and if there is the potential for overlap in the oxidation temperatures of CNTs and combustible components of the matrix. Thermal techniques could generally work in all matrices but the detection limit will be higher in matrices with more interferences as will be discussed in a subsequent section. Lower LODs may be achievable by first extracting the CNTs or decreasing the bias from other forms of organic carbon.

Quantification of CNTs (and other carbon nanomaterials $^{91-95}$ ) via isotopic labeling generally has fewer interferences than the other techniques, but obtaining isotopically enriched CNTs is typically challenging and/or expensive. Furthermore, this approach is only relevant for laboratory studies, not for detecting CNTs released into the environment. A related strategy, labeling CNTs with coatings containing a radioisotope, was used in many early biodistribution studies in the biomedical field, ${ }^{96-98}$ but has not been used in environmental or ecotoxicological studies. The challenge with this approach is that the accuracy of any measurement is contingent upon the radioactive tracer remaining associated with the CNTs.

Natural abundance, stable isotopic measurements (e.g., carbon-13 $)^{21}$ face similar limitations in that they require a CNT-free sample to which one can compare the isotopic composition in order to deploy the technique quantitatively. In laboratory studies, this is possible and more economically viable than radiolabeling techniques, but one has to carefully select CNT-free controls for quantifying CNTs in environmental samples. Furthermore, while the initial label is more expensive, the analytical techniques required to trace a carbon-14 label (i.e., liquid scintillation counting) are facile compared to the expert preparatory and analytical equipment required to trace natural-abundance isotopes (i.e., much lower levels of either carbon-14 or carbon-13 require accelerator mass spectrometers and isotope ratio mass spectrometers, respectively, and each with closed-tube-combustion preparation upstream). Nevertheless, the carbon source for SWCNTs produced using the high pressure carbon monoxide (HiPco) process is usually biomethane, ${ }^{21}$ which has a strong naturally depleted carbon- 13 signature, and such CNTs would be good candidates for using natural abundance, stable isotopic measurements. ${ }^{78}$

Evaluation of Potential Bias from Changes to the CNTs. In addition to interferences from different environmentally and biologically relevant matrices, changes that may occur to CNTs while in these matrices can also cause interferences for many of the quantification techniques (Supporting Information Table S2). The extent to which agglomeration, degradation, and wrapping by other molecules occurs depends on the physicochemical properties of the CNTs and of the matrix. It is well-known that CNTs will agglomerate in waters with sufficient ionic strength if they are not stabilized through, for example, a surfactant and that CNTs have a large capacity to adsorb natural organic matter. ${ }^{99-102}$ With regards to CNT agglomeration, while most techniques are sensitive to this change (e.g., most thermal techniques, Raman, NIRF, UV/vis/ NIR absorbance, and spICP-MS), some are not impacted by it (e.g., inorganic elemental analysis) or may even be enhanced (e.g., hyperspectral imaging). Potential interference from CNT agglomeration may result in, for example: (a) changes to the intensity or peak wavelengths in the spectrophotometry signals; (b) shifts in the thermal stability of the CNTs, which could prevent separation from other components in the matrix, such as black carbon or soot; or (c) hindering uniform distribution on a filter prior to analysis by TOT. Agglomeration may also increase the heterogeneity and affect representativeness of the subsamples in a matrix, which could lead to increased uncertainty. However, larger subsamples could help lower the uncertainty when feasible.

The literature shows variable results on the degradation of CNTs in environmental matrices. In some studies, degradation of carbon-14 labeled CNTs by enzymes or bacteria has been shown to be slow or not detectable ${ }^{77,78,103}$ except under specific situations with a special microbial consortium. ${ }^{77}$ In contrast, studies assessing the enzymatic degradation of noncarbon-14 labeled CNTs have often shown substantial degradation. ${ }^{82}$ The cause of this discrepancy is unclear. Studies on the photodegradation of CNTs have shown significant modifications to their surface structure or the loss of fluorescence under some experimental conditions. ${ }^{104,105}$ Thus, it is reasonable to assume that some degree of degradation could occur with CNTs in surface waters if they stay suspended for a sufficiently long period. Almost all quantification techniques are sensitive to CNT degradation and oxidation, although the degree of oxidation needed before it impacts quantification varies among techniques. One exception is carbon-14 analysis, which is not impacted by oxidation. In contrast, the degree of oxidation can directly impact CNT thermal properties and potentially the capacity to differentiate between CNTs and other forms of carbon present in the matrix using many of the thermal based techniques.

Wrapping of organic molecules around CNTs, such as proteins or NOM, may also impact most quantification techniques. Many of the potential changes that could cause biases, such as decreased signal intensity of a spectroscopic measurement or a change in the thermal stability of CNTs for thermal measurements, are similar to those discussed for degradation. However, the reason behind these changes is from the impact of the coating on the CNT properties rather than a change to the core CNT material itself as would occur during degradation. One challenge in discussing the potential bias from organic molecules wrapping around CNTs, and also agglomeration and oxidation/degradation, is that the magnitude of the bias relates partly to the degree of agglomeration, oxidation, and the quantity of organic molecules associated with the CNTs. It is possible to foresee examples when these changes in the environmental matrices could have a bias, but it is challenging to quantify the magnitude of the expected bias without information about the sample system (e.g., aqueous phase NOM concentrations can range between $5 \mathrm{mg} / \mathrm{L}$ and 50 $\mathrm{mg} / \mathrm{L}$ ) or the extent of oxidation. This information about the sample system or magnitude of likely changes could allow one to account for biases.

Being aware of the potential biases present in a sample from these changes to the CNTs and/or carrier matrix will support researchers in determining to what extent these factors may impact their measurements. However, it might be challenging to get this kind of information from samples with low CNT concentrations when there is a low signal-to-noise ratio. Environmentally relevant information on the rate of CNT modifications (e.g., oxidation) by environmental processes is 


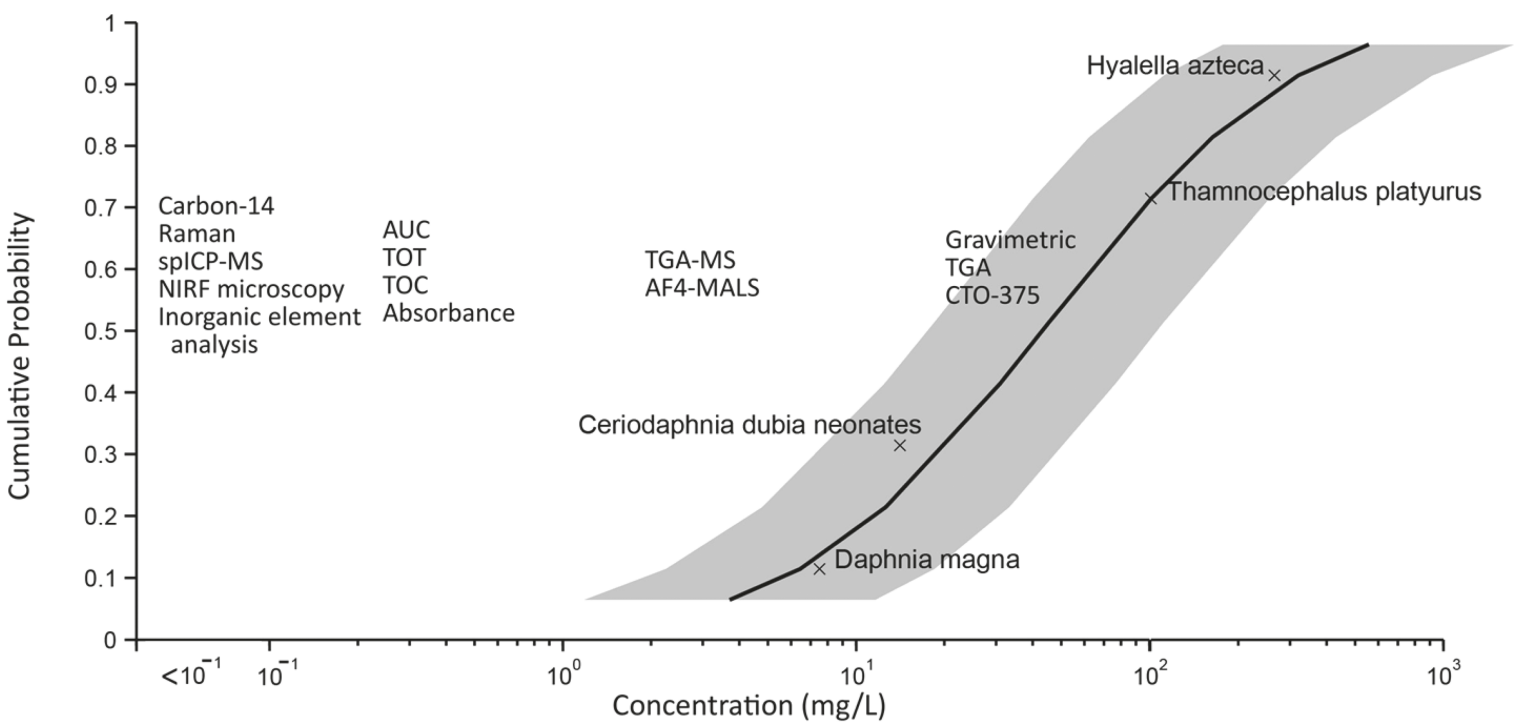

Figure 2. Comparison between detection limits for analytical techniques in a water-only media under optimal conditions juxtaposed with a species sensitivity distribution for CNTs for acute toxicity testing of pelagic organisms. For the species sensitivity distribution, the $95 \%$ confidence for the $\mathrm{LC}_{50}$ values is shown by the gray shaded area around the curve. The detection limits for the techniques span a range of 1 order of magnitude (e.g., 1 $\mathrm{mg} / \mathrm{L}$ to $10 \mathrm{mg} / \mathrm{L})$. This figure is modified with permission from Garner et al. ${ }^{189}$ Abbreviations: Asymmetric flow field flow fractionation with multiangle light scattering (aF4-MALS), analytical ultracentrifugation (AUC), chemothermal oxidation at $375{ }^{\circ} \mathrm{C}$ (CTO-375), near-infrared fluorescence (NIRF), single particle inductively coupled plasma-mass spectrometry (spICP-MS), thermal gravimetric analysis (TGA), thermal gravimetric analysis-mass spectrometry (TGA-MS), total organic carbon (TOC), thermal optical transmittance (TOT).

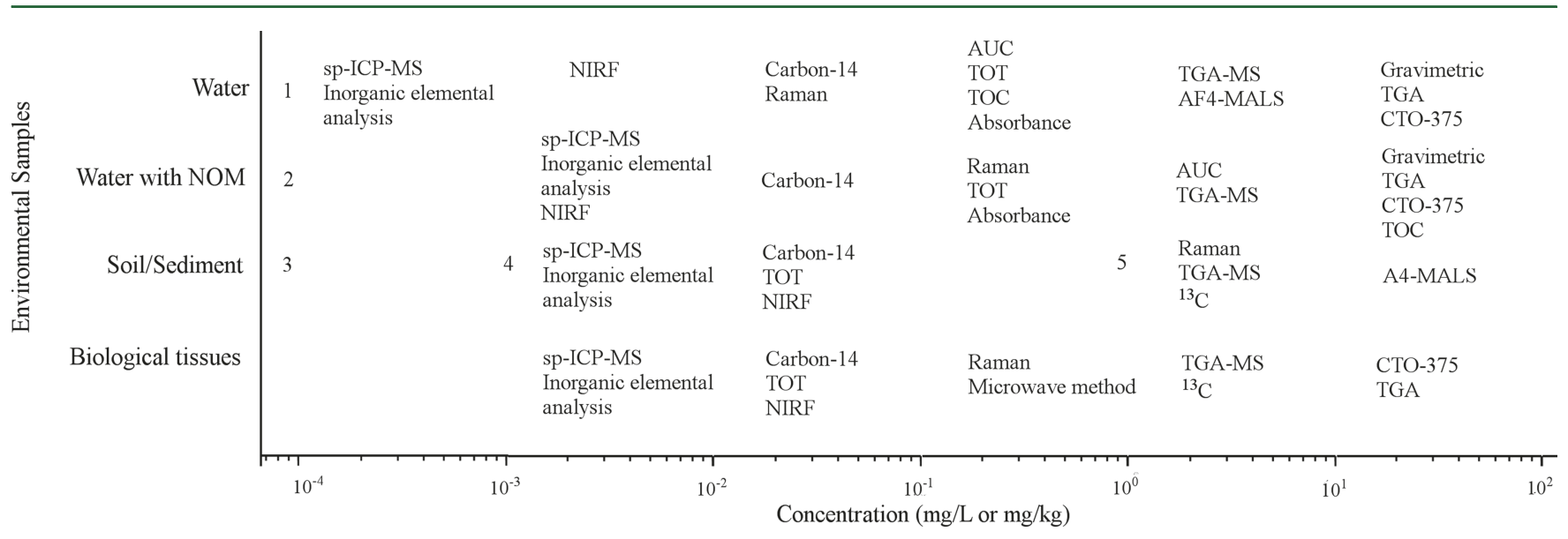

Figure 3. Detection limits for analytical techniques in various media under optimal conditions and modeled environmental concentrations $\left(1,{ }^{84} 2{ }^{85}\right.$ $\left.3{ }^{86} 4^{70}, 5^{19}\right)$; modeled environmental concentrations are not available for biological matrices. The detection limits for individual techniques span a range of 1 order of magnitude (e.g., $1 \mathrm{mg} / \mathrm{L}$ to $10 \mathrm{mg} / \mathrm{L}$ ). Abbreviations: Asymmetric flow field flow fractionation with multiangle light scattering (aF4-MALS), analytical ultracentrifugation (AUC), chemothermal oxidation at $375{ }^{\circ} \mathrm{C}$ (CTO-375), near-infrared fluorescence (NIRF), single particle inductively coupled plasma-mass spectrometry (spICP-MS), thermal gravimetric analysis (TGA), thermal gravimetric analysis-mass spectrometry (TGA-MS), total organic carbon (TOC), thermal optical transmittance (TOT).

limited, ${ }^{77,103,106-108}$ and systematic studies of those processes would be an enormous benefit to parallel efforts to quantify CNTs in the environment. While leaching of metal catalysts from the CNTs in environmental matrices is not explicitly covered in the above changes to the CNTs, it could dramatically impact analyses using spICP-MS or inorganic elemental analysis. The potential for changes in the catalyst particles associated with the CNTs in environmental matrices is the primary reason that these techniques are not more broadly used despite their low LODs.

Detection Limits of Quantification Techniques. The LOD for CNT quantification is one of the most critical performance metrics required to compare the various techniques. However, the definition of the LOD depends partly on how the CNT mass in a given sample is determined. The most common approach is for the whole sample, including CNTs, catalyst particles, and any carbonaceous impurities, to be included in the CNT mass used. It is possible instead to only use the CNTs themselves, at least for SWCNTs where, after purification procedures, the properties are more clearly distinguishable and high quality separation techniques exist. ${ }^{109}$ While additional metrics such as number or surface area concentrations are highly desired, ${ }^{63,110}$ the LOD values provided here are for mass concentrations.

There are two different approaches for determining the necessary LOD for quantifying contaminants in the environment. The first requires that the LOD is adequate for quantification of the contaminant at concentrations that may 
have harmful effects. An alternative requirement is for the analytical techniques to quantify the contaminant at the concentration that it is determined or estimated to be present in the environment. We have compared the LODs for the various analytical techniques using both approaches through comparing the LODs to a species sensitivity distribution for CNT acute toxicity to pelagic organisms (Figure 2) and to modeled environmental concentrations (Figure 3). Several trends are evident from reviewing these figures. First, the LODs in water span several orders of magnitude with some techniques only capable of quantifying CNTs in samples with concentrations greater than $10 \mathrm{mg} / \mathrm{L}$ (e.g., gravimetric measurements), while the most sensitive techniques can detect concentrations between $0.1 \mu \mathrm{g} / \mathrm{L}$ and $1 \mu \mathrm{g} / \mathrm{L}$ (e.g., spICP-MS) (Figure 3). Second, the lowest LOD values are for pristine water samples and increase with higher amounts of potential interferences in the matrix. Higher LODs are observed when NOM is present in waters, and even higher LODs are typically achieved when using CNT quantification techniques in soils, sediments, and biological tissues. Third, multiple techniques appear capable of quantifying CNTs at concentrations relevant for stock suspensions (e.g., $10 \mathrm{mg} \mathrm{L}^{-1}$ to $100 \mathrm{mg} \mathrm{L}^{-1}$ ) that could be used for pelagic aquatic toxicity testing (Figure 2). As discussed in more depth in a case study, some techniques could also be used to quantify the initial exposure concentration for ecotoxicity testing and the concentration after the experiment concludes. Fourth, the LODs are often orders of magnitude higher than the average modeled environmental concentration, but some are within the range of modeled sediment concentrations despite the lower LODs for CNT quantification in sediments. This suggests that it may be feasible to quantify CNTs in the environment under certain conditions. Overall, these figures can be used to assess which methods may offer suitable techniques for an intended purpose, as is described in more detail in the case studies. Alternatively, extraction or separation techniques (see above) may be necessary to selectively isolate and concentrate the CNTs prior to analysis.

Potential for Standardization. There are numerous reference materials (RM; e.g., UV/vis spectroscopy calibration standards) and standard methods that can support the standardization of CNT quantification techniques (Supporting Information Table S3). In addition, there are multiple CNT RMs and representative test materials (Supporting Information Table S4); RMs have assigned values for certain properties, whereas representative test materials are only guaranteed to be stable and homogeneous with respect to one or more specified properties but may be used in the development of test methods which assess properties other than those for which stability and homogeneity have been shown. ${ }^{111}$ Currently, three RMs are available for SWCNTs, while MWCNTs are only available as representative test materials. The careful characterization of the CNT RMs may be useful for the standardization of numerous techniques, given the wide range of properties that have been certified (i.e., the sources of uncertainty are thoroughly understood and the certified values have meaningful metrological traceability) or for which information values are provided (i.e., the sources of uncertainty are not fully understood or a limited number of analyses were performed). Standardized methods are also already available for characterization of CNTs (e.g., Raman spectroscopy and NIR fluorescence characterization) which could be modified to develop standard methods for CNT quantitation. ${ }^{42,112-118}$ In addition, a modified version of a NIOSH standard method for use of TOT for elemental carbon analysis (NIOSH Method 5040) could potentially be used for CNT quantification. However, the robustness of this method for CNTs will still need to be evaluated for different matrices. Extraction and separation procedures also need to be standardized but are not addressed in this section due to the limited number of studies on this topic. Research topics that would support the standardization of these techniques are described in the Future Research Topics section.

\section{CASE STUDIES}

In this section, five case studies will be used to illustrate how the quantitative methods described in this manuscript could be utilized to address hypothetical situations requiring CNT quantitation. The scenario for the first two case studies is that scientists are asked to determine whether the concentration of CNTs in a stream receiving effluent from a treatment plant where CNTs may be released is above $500 \mu \mathrm{g} \mathrm{L}^{-1}$; this concentration was chosen because it is approximately $50 \%$ of the lowest $\mathrm{LC}_{50}$ value of the species sensitivity distribution shown in Figure 2. This scenario will be discussed in the context of whether the CNT characteristics (e.g., SWCNT or MWCNT, catalyst materials, and thermal properties) are known a priori or not. In the third case study, scientists will be trying to measure the exposure concentration to organisms during a laboratory ecotoxicity experiment in a water only system with an organism that has an $\mathrm{EC}_{50}$ value (the concentration at which $50 \%$ of the organisms are affected) of $10 \mathrm{mg} \mathrm{L}^{-1}$ and the lowest concentration tested is $1 \mathrm{mg} \mathrm{L}^{-1}$. In the fourth case study, CNTs with known characteristics are accidentally released into a lake, and scientists are asked to determine the concentration in the lake sediment. In the fifth case study, "OECD Test 305: Bioaccumulation in fish: aqueous and dietary exposure" is performed using a known type of CNTs and the scientists need to quantify the concentration in the fish tissues.

Case I: CNTs with Known Characteristics Are Released into a River. First, identify the techniques that may have LODs better than $500 \mu \mathrm{g} \mathrm{L}^{-1}$ using Figure 3: UV/vis spectroscopy, inorganic elemental analysis, spICP-MS, NIRF, Raman spectroscopy, TOT, and carbon-14 labeling. Electron microscopy should, in principle, be able to detect CNTs at these concentrations, but it may be challenging to identify CNTs amidst the other particulate matter, and quantification will be challenging as discussed above. Of particle risk is the ability to collect a representative sample where the TEM thin section actually contains a statistically significant number of CNTs. Nevertheless, electron microscopy could be used for a qualitative assessment or to confirm the presence/absence of CNTs based on results from the quantitative analysis. Among the quantitative techniques, the choice of which technique to employ first would depend on numerous factors such as their availability and if the unique properties of the CNTs of interest may eliminate some of the analytical techniques from consideration (e.g., quality assurance (QA), techniques only applicable for SWCNTs would not be relevant for MWCNT quantification). For example, carbon-14 labeling would not be relevant for field measurements, while NIRF would only be applicable for SWCNTs. ${ }^{15}$ In addition, Raman spectroscopy analysis would require preconcentration of the sample to yield the desired LOD which may be challenging. ${ }^{13}$ Next, the properties of the river water prior to the discharge location (e.g., thermal profile, elemental composition and organic matter 
concentration of the water) could be evaluated to assess what biases may be encountered during CNT quantification for various techniques. If it is possible to obtain the CNTs of interest, a next step would be to prepare a CNT dispersion, mix the dispersion with streamwater prior to the location of discharge, and then analyze the water using the quantification technique(s) to determine relevant QA/quality control (QC) characteristics such as the LOD, reproducibility, bias, signal-tonoise ratio, and linearity of calibration curve. It may also be important to test the stability of the CNT in the water prior to the discharge location to assess if agglomeration or oxidation of the CNT could cause a bias; if agglomeration causes a significant bias, it may be possible to disperse the samples such as by adding a surfactant or sonicating the sample. If the QA/ QC characteristics are sufficient to provide the needed level of statistical significance for the quantification measurement, the final step would be to analyze the test samples.

Case II: CNTs with Unknown Characteristics Are Released into a River. The process is substantially more complicated if characteristics of the CNT to be detected are unknown. First, it would be helpful to obtain water samples before and after the point source discharge location. It would then be possible to perform some measurements to try to determine if characteristics of the river water reflective of CNT characteristics are changed. For example, an inorganic elemental analysis or spICP-MS analysis of the river waters could be conducted to assess if uncommon elements (e.g., yttrium) or ratios of elements (e.g., cobalt to molybdenum) often used for CNT catalysts are present at different concentrations before and after the location of discharge; measuring these samples before and after filtering could reveal if the metals are associated with particles such as CNTs. One distinct advantage of the metal analysis techniques is that the LODs for many of these elements are orders of magnitude better than the limit of detection needed for the CNTs (Figure 3). This information supported by other characterization techniques (e.g., TEM analysis to assess if SWCNTs or MWCNTs can be identified) could help determine the type of CNT being used. An alternate first step would be to obtain a sample directly at the discharge location and conduct these analyses. The advantage of this approach is that there would not be dilution of the CNTs, but the matrix may be substantially more complex (e.g., wastewater treatment plant effluent). A next step is to spike known concentrations of the specific CNT if identified, or alternatively RM SWCNTs and representative test material MWCNTs, into the river water prior to the discharge location and determine the QA/QC characteristics for the selected techniques and the extent to which agglomeration or oxidation could influence the results. If acceptable results can be obtained with the specific CNT (if identified) or the RM CNTs, then analysis can be conducted on the river sample after the location of discharge.

Case III: Laboratory Ecotoxicity Study. The third case study involves a laboratory ecotoxicity experiment during which the concentration remaining suspended during the experiment needs to be quantified. Depending upon what organism is tested, there may be interferences such as algae or bacteria which remain suspended and may have CNTs associated with them. If it is straightforward to separate the test organisms from the media with suspended CNTs, numerous techniques may be applicable for quantifying the initial CNT concentration in suspension $\left(\geq 1 \mathrm{mg} \mathrm{L}^{-1}\right)$ (see Figure 2 ). The techniques available to determine the change in concentration during the experiment depend on the LOD needed for these measurements. For example, if it is unlikely that the CNT will settle during the experiment, numerous techniques would enable measurements to show that the concentration remained within $20 \%$ of the initial concentration, the desired maximum concentration loss indicated in many OECD tests. ${ }^{63}$ However, if substantial settling occurs, it is necessary to determine the lowest detection limit needed (e.g., $0.1 \mathrm{mg} \mathrm{L}^{-1}$ to quantify a loss in concentration of $90 \%$ of the initial concentration). When measuring the CNT concentration dispersed in tests with suspended unicellular organisms or small multicellular organisms (e.g., Tetrahymena thermophila), the cells themselves may cause biases or require the extraction of the CNTs. It is also unclear if CNTs that are suspended but associated with cells should be counted as part of the total suspended concentration. Nevertheless, many techniques could likely still be used to quantify the total suspended concentration but control experiments to test for potential biases from the cells and the matrix would need to be conducted prior to starting the experiment.

Case Study IV: Quantification of CNTs with Known Characteristics in Lake Sediment. Quantifying CNTs in sediments is substantially more difficult than in water samples. As shown in Figure 3, the LODs for most techniques are at least an order of magnitude higher in soils and sediments compared to in waters. To quantify CNTs in sediments, a first step would be to obtain "clean" sediment from another water body ideally with similar sediment characteristics. Because the CNT type is known in this case study, it is possible to spike this clean sediment with CNTs and then assess the quality of the analytical results (e.g., linearity, LOD, etc.). The suitable techniques for this analysis will depend upon instrument availability, the type of CNT (e.g., NIRF after CNT extraction has been shown to be a valuable technique for analysis of SWCNTs in sediments ${ }^{15}$ but is not applicable to MWCNTs), and the estimated range of probable CNT concentrations in the sediment. If satisfactory LODs are not available for the available techniques in the reference sediment, it may be necessary to investigate extraction or separation methods to decrease the LOD (e.g., refs 15 and 46). Given the low detection limits obtained using NIRF after extraction $(62 \mu \mathrm{g} / \mathrm{kg}){ }^{15}$ challenges with obtaining a better LOD are likely only to be problematic for MWCNTs unless the SWCNTs are oxidized or modified to the extent that NIRF is not applicable or NIRF is not available for sample analysis.

Case Study V: Quantification of CNT in Fish after a Standard Toxicity Test. Assessing potential bioaccumulation of chemicals in organisms is an important component of risk assessment of chemicals. One frequently used test is OECD method 305: Bioaccumulation in fish: aqueous and dietary exposure. ${ }^{119}$ Again, the LODs for quantifying CNTs in organism tissues are greater than those in water, yet similar to the LODs for soils and sediments (Figure 3). While the whole fish is usually analyzed in this method, it may be beneficial to test the CNT biodistribution in addition to the total concentration in the fish. This is important because CNT translocation across the gut tract is rarely observed in ecotoxicological studies. ${ }^{27,31,120,121}$ If the biodistribution of SWCNTs is evaluated, then the technique with the best LOD is NIRF microscopy which has been reported to detect individual SWCNTs. ${ }^{31,121}$ If this instrument is not available, Raman microscopy and electron microscopy can be used to assess biodistribution of CNTs in organisms although it is important 
to carefully avoid artifacts; ${ }^{27,43,122,123}$ however, one should note that $\mathrm{G} / \mathrm{D}$ ratios are strongly influenced by any $s p^{2}$ or $s p^{3}$ hybridized carbons present in the organism for Raman microscopy analysis. Other microscopic approaches such as photothermal/photoacoustic imaging have also been successfully used to assess the distribution of CNTs in plants, yet are infrequently available (Figure 1). ${ }^{24}$ To quantify the total concentration of CNTs in the fish, it is possible to use NIRF microscopy for SWCNTs, ${ }^{31}$ but extraction from the fish tissue will likely be needed for MWCNTs. An extraction procedure has been published for MWCNTs in rat lungs followed by quantification using TOT, ${ }^{23}$ but this approach has not yet been used in tandem with other quantification techniques or with fish tissues. If carbon-14 labeled CNTs are available, assessing uptake by and biodistribution in fish through carbon-14 labeling is a viable approach. ${ }^{124}$ The microwave method has also shown promise for detecting MWCNTs in biological samples (e.g., earthworms) but requires custom built equipment. $^{62,125}$

\section{FUTURE RESEARCH TOPICS}

The analysis that we present here on the current state of the science with regards to quantification of CNTs in matrices relevant for nanotechnology environmental health and safety measurements also reveals several key future research topics to move this field forward. First, most of the quantification techniques developed for aqueous environments will have potential biases or a higher LOD in complex matrices such as soils and biological tissues. Thus, the continued development of CNT extraction and separation procedures for environmental and biological matrices is a critical topic for additional research. Nevertheless, addressing the quality of the CNT separation depends in part on the robustness and precision of the subsequent analytical techniques, which also need to be improved. Second, sensitivity analyses of techniques can provide relevant information regarding the robustness of an experimental procedure to minor changes to a protocol and the contributions of various steps to the total uncertainty of the result. This approach and related approaches such as cause-andeffect analysis can highlight which steps of a protocol need to be carefully followed to ensure a reliable result and which steps are less critical. ${ }^{126}$ Third, interlaboratory comparisons, where multiple laboratories use the same protocol, are needed to standardize the more mature techniques and extraction and separation procedures. While it is necessary to assess many topics related to analytical precision of a single laboratory (e.g., within and between operator variability, instrument to instrument variability, day-to-day variability, all contributing to the within-laboratory repeatability), interlaboratory comparisons can provide unique information about the comparability of results among laboratories (i.e., between-laboratory reproducibility) and potential factors in the protocols that need to be controlled to standardize the procedure. Such information is needed to provide estimates of the bias and precision of an analytical method. Fourth, analyzing an individual or set of homogenized test samples using multiple techniques will be helpful in highlighting method specific biases and the comparability of results among methods (e.g., similarly to a black carbon quantification ring trial ${ }^{127}$ ). This differs from interlaboratory comparisons in that a single sample is analyzed by multiple techniques, as opposed to different laboratories using the same technique and test method. Similar results among orthogonal techniques would lead to greater confidence in the results of the methods while different results could yield insights into biases, strengths, and limitations of different methods. For example, in a recent study on the fate of SWCNTs in a mesocosm, an experimental setup designed to simulate the natural environment that often includes multiple species and which has been used in several nanotoxicity studies, ${ }^{128,129}$ both NIRF and inorganic elemental analysis were used on the same samples. ${ }^{29}$ The agreement among these methods suggested that inorganic elemental analysis may be a useful approach in these complex matrices if the catalysts used to synthesize the CNTs are of an element with low concentrations in the matrix (e.g., Mo). ${ }^{29} \mathrm{~A}$ similar approach could be used to compare among different extraction or separation techniques with a single sample. Fifth, isotopically enriched or depleted CNTs ${ }^{21,78}$ could be used to help develop other orthogonal techniques given that isotopic techniques often have the fewest biases for many of the matrices and changes that could occur to the CNTs in these matrices. Such an approach was used by Schierz et al. to develop the NIRF technique for quantification of SWCNTs in sediments after extraction by also testing the extraction procedure with carbon14 labeled SWCNTs. ${ }^{15}$ Sixth, using extraction and/or separation techniques in combination such as AF4 followed by capillary electrophoresis could be another promising avenue for future research. Lastly, almost all quantitative techniques require known CNTs to yield information about their characteristic information (e.g., thermal profile, metal catalyst, impurities, NIR spectra, and Raman signature). Additional work is needed to develop techniques for quantification of unknown CNTs in an environmental or biological matrix. Along these lines, the impact of CNT heterogeneities (e.g., different lengths) on their quantification could also be helpful.

\section{ASSOCIATED CONTENT}

\section{S Supporting Information}

The Supporting Information is available free of charge on the ACS Publications website at DOI: 10.1021/acs.est.5b05647.

Tables describing potential matrix interferences and interferences from changes to the CNTs on selected CNT quantification techniques, standard reference material carbon nanotubes, and standards and references materials related to standardization of carbon nanotube quantification techniques (PDF)

\section{AUTHOR INFORMATION}

\section{Corresponding Author}

*Phone (301)-975-8142; e-mail: Elijah.Petersen@nist.gov.

\section{Present Address}

$\nabla$ (D.X.F.-C.) 2042 Dwight Way, Berkeley, California 94704, United States.

\section{Notes}

The authors declare no competing financial interest.

\section{ACKNOWLEDGMENTS}

The contributions of A.G. and T.D.B. were provided as part of the project "Effects of NANOparticles on beneficial soil MIcrobes and CROPS (NANOMICROPS)", within the Swiss National Research Programme NRP 64 "Opportunities and Risks of Nanomaterials”. AG and TDB thank the Swiss National Science Foundation (SNSF) for financial support. DLP acknowledges support from NSF CBET \# 1336794. D.X. Flores-Cervantes is very grateful to Hans-Peter Kohler for his 
continuous support and advice, and thanks the SNSF through the NRP 64 (Project Biocarb) for the financial support. P.W. acknowledges support from NSF CBET \#1336542 and EEC\#1449500, and US EPA \#RD83558001. We thank Dr. P. Lee Ferguson (Duke University) for helpful discussions.

\section{REFERENCES}

(1) De Volder, M. F.; Tawfick, S. H.; Baughman, R. H.; Hart, A. J. Carbon nanotubes: present and future commercial applications. Science 2013, 339 (6119), 535-9.

(2) Piccinno, F.; Gottschalk, F.; Seeger, S.; Nowack, B., Industrial production quantities and uses of ten engineered nanomaterials in Europe and the world. J. Nanopart. Res. 2012, 14, (9), Article number 1109.10.1007/s11051-012-1109-9

(3) Helland, A.; Wick, P.; Koehler, A.; Schmid, K.; Som, C. Reviewing the environmental and human health knowledge base of carbon nanotubes. Environ. Health Perspect. 2007, 115 (8), 11251131.

(4) Petersen, E. J.; Zhang, L. W.; Mattison, N. T.; O'Carroll, D. M.; Whelton, A. J.; Uddin, N.; Nguyen, T.; Huang, Q. G.; Henry, T. B.; Holbrook, R. D.; Chen, K. L. Potential release pathways, environmental fate, and ecological risks of carbon nanotubes. Environ. Sci. Technol. 2011, 45 (23), 9837-9856.

(5) Mauter, M. S.; Elimelech, M. Environmental applications of carbon-based nanomaterials. Environ. Sci. Technol. 2008, 42 (16), $5843-5859$

(6) Shen, M. W.; Wang, S. H.; Shi, X. Y.; Chen, X. S.; Huang, Q. G.; Petersen, E. J.; Pinto, R. A.; Baker, J. R.; Weber, W. J., Jr. Polyethyleneimine-mediated functionalization of multiwalled carbon nanotubes: Synthesis, characterization, and in vitro toxicity assay. $J$. Phys. Chem. C 2009, 113 (8), 3150-3156.

(7) Shi, X. Y.; Wang, S. H.; Shen, M. W.; Antwerp, M. E.; Chen, X. S.; Li, C.; Petersen, E. J.; Huang, Q. G.; Weber, W. J., Jr.; Baker, J. R. Multifunctional dendrimer-modified multiwalled carbon nanotubes: Synthesis, characterization, and in vitro cancer cell targeting and imaging. Biomacromolecules 2009, 10 (7), 1744-1750.

(8) Lee, J.; Mahendra, S.; Alvarez, P. J. J. Nanomaterials in the construction industry: A review of their applications and environmental health and safety considerations. ACS Nano 2010, 4 (7), $3580-3590$

(9) Plata, D. L.; Ferguson, P. L.; Westerhoff, P. Express It in Numbers: Efforts to Quantify Engineered Nanoparticles in Environmental Matrices Advance. Environ. Sci. Technol. 2012, 46 (22), 1224312245 .

(10) Selck, H.; Handy, R. D.; Fernandes, T. F.; Klaine, S. J.; Petersen, E. J. Nanomaterials in the aquatic environment: A European UnionUnited States perspective on the status of ecotoxicity testing, research priorities, and challenges ahead. Environ. Toxicol. Chem. 2016, 35 (5), 1055-1067.

(11) Bahr, J. L.; Mickelson, E. T.; Bronikowski, M. J.; Smalley, R. E.; Tour, J. M. Dissolution of small diameter single-wall carbon nanotubes in organic solvents? Chem. Commun. 2001, No. 2, 193-194.

(12) Cherukuri, P.; Bachilo, S. M.; Litovsky, S. H.; Weisman, R. B. Near-infrared fluorescence microscopy of single-walled carbon nanotubes in phagocytic cells. J. Am. Chem. Soc. 2004, 126 (48), 1563815639 .

(13) Lopez-Lorente, A. I.; Simonet, B. M.; Valcarcel, M. Determination of carboxylic SWCNTs in river water by microextraction in ionic liquid and determination by Raman spectroscopy. Talanta 2013, 105, 75-79.

(14) Plata, D. L.; Reddy, C. M.; Gschwend, P. M. ThermogravimetryMass Spectrometry for Carbon Nanotube Detection in Complex Mixtures. Environ. Sci. Technol. 2012, 46 (22), 12254-12261.

(15) Schierz, A.; Parks, A. N.; Washburn, K. M.; Chandler, G. T.; Ferguson, P. L. Characterization and Quantitative Analysis of SingleWalled Carbon Nanotubes in the Aquatic Environment Using NearInfrared Fluorescence Spectroscopy. Environ. Sci. Technol. 2012, 46 (22), 12262-12271.
(16) Doudrick, K.; Herckes, P.; Westerhoff, P. Detection of Carbon Nanotubes in Environmental Matrices Using Programmed Thermal Analysis. Environ. Sci. Technol. 2012, 46 (22), 12246-12253.

(17) Hyung, H.; Fortner, J. D.; Hughes, J. B.; Kim, J. H. Natural organic matter stabilizes carbon nanotubes in the aqueous phase. Environ. Sci. Technol. 2007, 41 (1), 179-184.

(18) Sobek, A.; Bucheli, T. D. Testing the resistance of single- and multi-walled carbon nanotubes to chemothermal oxidation used to isolate soots from environmental samples. Environ. Pollut. 2009, 157 (4), 1065-1071.

(19) Koelmans, A. A.; Nowack, B.; Wiesner, M. R. Comparison of manufactured and black carbon nanoparticle concentrations in aquatic sediments. Environ. Pollut. 2009, 157 (4), 1110-6.

(20) Mansfield, E.; Kar, A.; Hooker, S. A. Applications of TGA in quality control of SWCNTs. Anal. Bioanal. Chem. 2010, 396 (3), $1071-1077$

(21) Plata, D. L.; Gschwend, P. M.; Reddy, C. M., Industrially synthesized single-walled carbon nanotubes: compositional data for users, environmental risk assessments, and source apportionment. Nanotechnology 2008, 19 (18), Article Number: 185706.

(22) Reed, R. B.; Goodwin, D. G.; Marsh, K. L.; Capracotta, S. S.; Higgins, C. P.; Fairbrother, D. H.; Ranville, J. F. Detection of single walled carbon nanotubes by monitoring embedded metals. Environ. Sci. Proc. Imp. 2013, 15 (1), 204-213.

(23) Doudrick, K.; Corson, N.; Oberdörster, G.; Eder, A. C.; Herckes, P.; Halden, R. U.; Westerhoff, P. Extraction and Quantification of Carbon Nanotubes in Biological Matrices with Application to Rat Lung Tissue. ACS Nano 2013, 7 (10), 8849-8856.

(24) Khodakovskaya, M. V.; de Silva, K.; Nedosekin, D. A.; Dervishi, E.; Biris, A. S.; Shashkov, E. V.; Galanzha, E. I.; Zharov, V. P. Complex genetic, photothermal, and photoacoustic analysis of nanoparticleplant interactions. Proc. Natl. Acad. Sci. U. S. A. 2011, 108 (3), 10281033.

(25) Petersen, E. J.; Pinto, R. A.; Zhang, L.; Huang, Q. G.; Landrum, P. F.; Weber, W. J. Effects of polyethyleneimine-mediated functionalization of multi-walled carbon nanotubes on earthworm bioaccumulation and sorption by soils. Environ. Sci. Technol. 2011, 45 (8), 37183724.

(26) Petersen, E. J.; Pinto, R. A.; Mai, D. J.; Landrum, P. F.; Weber, W. J., Jr. Influence of Polyethyleneimine Graftings of Multi-Walled Carbon Nanotubes on their Accumulation and Elimination by and Toxicity to Daphnia magna. Environ. Sci. Technol. 2011, 45 (3), 11331138.

(27) Edgington, A. J.; Petersen, E. J.; Herzing, A. A.; Podila, R.; Rao, A.; Klaine, S. J. Microscopic investigation of single-wall carbon nanotube uptake by Daphnia magna. Nanotoxicology 2014, 8 (S1), 210.

(28) Zhang, L.; Petersen, E. J.; Huang, Q. G. Phase distribution of ${ }^{14} \mathrm{C}$-labeled multiwalled carbon nanotubes in aqueous systems containing model solids: Peat. Environ. Sci. Technol. 2011, 45 (4), $1356-1362$

(29) Schierz, A.; Espinasse, B.; Wiesner, M. R.; Bisesi, J. H.; SaboAttwood, T.; Ferguson, P. L. Fate of single walled carbon nanotubes in wetland ecosystems. Environ. Sci.: Nano 2014, 1 (6), 574-583.

(30) Ferguson, P. L.; Chandler, G. T.; Templeton, R. C.; Demarco, A.; Scrivens, W. A.; Englehart, B. A. Influence of sediment-amendment with single-walled carbon nanotubes and diesel soot on bioaccumulation of hydrophobic organic contaminants by benthic invertebrates. Environ. Sci. Technol. 2008, 42 (10), 3879-3885.

(31) Bisesi, J. H.; Merten, J.; Liu, K.; Parks, A. N.; Afrooz, A.; Glenn, J. B.; Klaine, S. J.; Kane, A. S.; Saleh, N. B.; Ferguson, P. L.; SaboAttwood, T. Tracking and Quantification of Single-Walled Carbon Nanotubes in Fish Using Near Infrared Fluorescence. Environ. Sci. Technol. 2014, 48 (3), 1973-1983.

(32) Hanna, S. K.; Miller, R. J.; Lenihan, H. S. Deposition of carbon nanotubes by a marine suspension feeder revealed by chemical and isotopic tracers. J. Hazard. Mater. 2014, 279, 32-37. 
(33) Jeong, J.; Lee, Y. J.; Hwang, Y. S.; Hong, I. S. Selective detection and quantification of carbon nanotubes in soil. Environ. Toxicol. Chem. 2015, 34 (9), 1969-1974.

(34) Petersen, E. J.; Henry, T. B. Methodological considerations for testing the ecotoxicity of carbon nanotubes and fullerenes: Review. Environ. Toxicol. Chem. 2012, 31 (1), 60-72.

(35) Su, Y.; Yan, X. M.; Pu, Y. B.; Xiao, F.; Wang, D. S.; Yang, M. Risks of Single-Walled Carbon Nanotubes Acting as ContaminantsCarriers: Potential Release of Phenanthrene in Japanese Medaka (Oryzias latipes). Environ. Sci. Technol. 2013, 47 (9), 4704-4710.

(36) Chilek, J. L.; Wang, R. H.; Draper, R. K.; Pantano, P. Use of Gel Electrophoresis and Raman Spectroscopy to Characterize the Effect of the Electronic Structure of Single-Walled Carbon Nanotubes on Cellular Uptake. Anal. Chem. 2014, 86 (6), 2882-2887.

(37) Wang, R. H.; Mikoryak, C.; Chen, E.; Li, S.; Pantano, P.; Draper, R. K. Gel Electrophoresis Method to Measure the Concentration of Single-Walled Carbon Nanotubes Extracted from Biological Tissue. Anal. Chem. 2009, 81 (8), 2944-2952.

(38) Tong, L.; Liu, Y. X.; Dolash, B. D.; Jung, Y.; Slipchenko, M. N.; Bergstrom, D. E.; Cheng, J. X. Label-free imaging of semiconducting and metallic carbon nanotubes in cells and mice using transient absorption microscopy. Nat. Nanotechnol. 2012, 7 (1), 56-61.

(39) von der Kammer, F.; Ferguson, P. L.; Holden, P. A.; Masion, A.; Rogers, K. R.; Klaine, S. J.; Koelmans, A. A.; Horne, N.; Unrine, J. M. Analysis of engineered nanomaterials in complex matrices (environment and biota): General considerations and conceptual case studies. Environ. Toxicol. Chem. 2012, 31 (1), 32-49.

(40) Herrero-Latorre, C.; Alvarez-Mendez, J.; Barciela-Garcia, J.; Garcia-Martin, S.; Pena-Crecente, R. M. Characterization of carbon nanotubes and analytical methods for their determination in environmental and biological samples: A review. Anal. Chim. Acta 2015, 853, 77-94.

(41) Fagan, J. A.; Bauer, B. J.; Hobbie, E. K.; Becker, M. L.; Walker, A. R. H.; Simpson, J. R.; Chun, J.; Obrzut, J.; Bajpai, V.; Phelan, F. R.; Simien, D.; Huh, J. Y.; Migler, K. B. Carbon Nanotubes: Measuring Dispersion and Length. Adv. Mater. 2011, 23 (3), 338-348.

(42) Decker, J. E.; Walker, A. R. H.; Bosnick, K.; Clifford, C. A.; Dai, L.; Fagan, J.; Hooker, S.; Jakubek, Z. J.; Kingston, C.; Makar, J.; Mansfield, E.; Postek, M. T.; Simard, B.; Sturgeon, R.; Wise, S.; Vladar, A. E.; Yang, L.; Zeisler, R. Sample preparation protocols for realization of reproducible characterization of single-wall carbon nanotubes. Metrologia 2009, 46 (6), 682-692.

(43) Petersen, E. J.; Henry, T. B.; Zhao, J.; MacCuspie, R. I.; Kirschling, T. L.; Dobrovolskaia, M. A.; Hackley, V.; Xing, B.; White, J. C. Identification and Avoidance of Potential Artifacts and Misinterpretations in Nanomaterial Ecotoxicity Measurements. Environ. Sci. Technol. 2014, 48 (8), 4226-4246.

(44) Worle-Knirsch, J. M.; Pulskamp, K.; Krug, H. F. Oops they did it again! Carbon nanotubes hoax scientists in viability assays. Nano Lett. 2006, 6 (6), 1261-1268.

(45) Jakubek, L. M.; Marangoudakis, S.; Raingo, J.; Liu, X. Y.; Lipscombe, D.; Hurt, R. H. The inhibition of neuronal calcium ion channels by trace levels of yttrium released from carbon nanotubes. Biomaterials 2009, 30 (31), 6351-6357.

(46) Gogos, A.; Kaegi, R.; Zenobi, R.; Bucheli, T. D. Capabilities of asymmetric flow field-flow fractionation coupled to multi-angle light scattering to detect carbon nanotubes in soot and soil. Environ. Sci.: Nano 2014, 1 (6), 584-594.

(47) Tagmatarchis, N.; Zattoni, A.; Reschiglian, P.; Prato, M. Separation and purification of functionalised water-soluble multiwalled carbon nanotubes by flow field-flow fractionation. Carbon 2005, 43 (9), 1984-1989.

(48) Niyogi, S.; Hu, H.; Hamon, M. A.; Bhowmik, P.; Zhao, B.; Rozenzhak, S. M.; Chen, J.; Itkis, M. E.; Meier, M. S.; Haddon, R. C. Chromatographic Purification of Soluble Single-Walled Carbon Nanotubes (s-SWNTs). J. Am. Chem. Soc. 2001, 123 (4), 733-734.

(49) Fagan, J. A.; Khripin, C. Y.; Batista, C. A. S.; Simpson, J. R.; Haroz, E. H.; Walker, A. R. H.; Zheng, M. Isolation of Specific Small-
Diameter Single-Wall Carbon Nanotube Species via Aqueous TwoPhase Extraction. Adv. Mater. 2014, 26 (18), 2800-2804.

(50) Pycke, B. F. G.; Benn, T. M.; Herckes, P.; Westerhoff, P.; Halden, R. U. Strategies for quantifying C-60 fullerenes in environmental and biological samples and implications for studies in environmental health and ecotoxicology. TrAC, Trends Anal. Chem. 2011, 30 (1), 44-57.

(51) Pycke, B. F. G.; Chao, T. C.; Herckes, P.; Westerhoff, P.; Halden, R. U. Beyond $\mathrm{nC}(60)$ : strategies for identification of transformation products of fullerene oxidation in aquatic and biological samples. Anal. Bioanal. Chem. 2012, 404 (9), 2583-2595.

(52) Isaacson, C. W.; Kleber, M.; Field, J. A. Quantitative analysis of fullerene nanomaterials in environmental systems: A critical review. Environ. Sci. Technol. 2009, 43 (17), 6463-6474.

(53) Wang, J. F.; Wages, M.; Yu, S. Y.; Maul, J. D.; Mayer, G.; HopeWeeks, L.; Cobb, G. P. Bioaccumulation of fullerene $\left(\mathrm{C}_{60}\right)$ and corresponding catalase elevation in Lumbriculus variegatus. Environ. Toxicol. Chem. 2014, 33 (5), 1135-1141.

(54) Pakarinen, K.; Petersen, E. J.; Leppanen, M. T.; Akkanen, J.; Kukkonen, J. V. K. Adverse effects of fullerenes (nC(60)) spiked to sediments on Lumbriculus variegatus (Oligochaeta). Environ. Pollut. 2011, 159 (12), 3750-3756.

(55) Tervonen, K.; Waissi, G.; Petersen, E. J.; Akkanen, J.; Kukkonen, J. V. K. Analysis of fullerene- $\mathrm{C}_{60}$ and kinetic measurements for its accumulation and depuration in Daphnia magna. Environ. Toxicol. Chem. 2010, 29 (5), 1072-1078.

(56) Pakarinen, K.; Petersen, E. J.; Alvila, L.; Waissi-Leinonen, G. C.; Akkanen, J.; Leppänen, M. T.; Kukkonen, J. V. K. A screening study on the fate of fullerenes (nC60) and their toxic implications in natural freshwaters. Environ. Toxicol. Chem. 2013, 32 (6), 1224-1232.

(57) Petersen, E. J.; Lam, T.; Gorham, J. M.; Scott, K. C.; Long, C. J.; Stanley, D.; Sharma, R.; Liddle, J. A.; Pellegrin, B.; Nguyen, T. Methods to assess the impact of UV irradiation on the surface chemistry and structure of multiwall carbon nanotube epoxy nanocomposites. Carbon 2014, 69, 194-205.

(58) Nowack, B.; David, R. M.; Fissan, H.; Morris, H.; Shatkin, J. A.; Stintz, M.; Zepp, R.; Brouwer, D. Potential release scenarios for carbon nanotubes used in composites. Environ. Int. 2013, 59, 1-11.

(59) Kingston, C.; Zepp, R.; Andrady, A.; Boverhof, D.; Fehir, R.; Hawkins, D.; Roberts, J.; Sayre, P.; Shelton, B.; Sultan, Y.; Vejins, V.; Wohlleben, W. Release characteristics of selected carbon nanotube polymer composites. Carbon 2014, 68, 33-57.

(60) Wohlleben, W.; Meier, M. W.; Vogel, S.; Landsiedel, R.; Cox, G.; Hirth, S.; Tomovic, Z. Elastic CNT-polyurethane nanocomposite: synthesis, performance and assessment of fragments released during use. Nanoscale 2013, 5 (1), 369-380.

(61) Green, J. M.; Irin, F.; Canas, J. E.; Saed, M. A. Carbon 2012, 50, 4441.

(62) Irin, F.; Shrestha, B.; Canas, J. E.; Saed, M. A.; Green, M. J. Detection of carbon nanotubes in biological samples through microwave-induced heating. Carbon 2012, 50 (12), 4441-4449.

(63) Petersen, E. J.; Diamond, S. A.; Kennedy, A. J.; Goss, G. G.; Ho, K.; Lead, J.; Hanna, S. K.; Hartmann, N. B.; Hund-Rinke, K.; Mader, B.; Manier, N.; Pandard, P.; Salinas, E. R.; Sayre, P. Adapting OECD Aquatic Toxicity Tests for Use with Manufactured Nanomaterials: Key Issues and Consensus Recommendations. Environ. Sci. Technol. 2015, 49 (16), 9532-9547.

(64) Li, Z. F.; Luo, G. H.; Zhou, W. P.; Wei, F.; Xiang, R.; Liu, Y. P. The quantitative characterization of the concentration and dispersion of multi-walled carbon nanotubes in suspension by spectrophotometry. Nanotechnology 2006, 17 (15), 3692-3698.

(65) Cerrillo, C.; Barandika, G.; Igartua, A.; Areitioaurtena, O.; Marcaide, A.; Mendoza, G. Ecotoxicity of multiwalled carbon nanotubes: Standardization of the dispersion methods and concentration measurements. Environ. Toxicol. Chem. 2015, 34 (8), 18541862.

(66) Porter, A. E.; Gass, M.; Muller, K.; Skepper, J. N.; Midgley, P. A.; Welland, M. Direct imaging of single-walled carbon nanotubes in cells. Nat. Nanotechnol. 2007, 2 (11), 713-717. 
(67) Mavrocordatos, D.; Perret, D. Non-artifacted specimen preparation for transmission electron microscopy of submicron soil particles. Commun. Soil Sci. Plant Anal. 1995, 26 (15-16), 2593-2602.

(68) Gogos, A. Engineered nanomaterials in the agricultural environment: current state of applications and development of analytical methods. Ph. D. Thesis No. 22589. Swiss Federal Insitute of Technology (ETH), 2015.

(69) Prasad, A.; Lead, J. R.; Baalousha, M. An electron microscopy based method for the detection and quantification of nanomaterial number concentration in environmentally relevant media. Sci. Total Environ. 2015, 537, 479-486.

(70) Gottschalk, F.; Sun, T. Y.; Nowack, B. Environmental concentrations of engineered nanomaterials: Review of modeling and analytical studies. Environ. Pollut. 2013, 181, 287-300.

(71) Schwab, F.; Bucheli, T. D.; Lukhele, L. P.; Magrez, A.; Nowack, B.; Sigg, L.; Knauer, K. Are Carbon Nanotube Effects on Green Algae Caused by Shading and Agglomeration? Environ. Sci. Technol. 2011, 45 (14), 6136-6144.

(72) Pohl, K.; Cantwell, M.; Herckes, P.; Lohmann, R. Black carbon concentrations and sources in the marine boundary layer of the tropical Atlantic Ocean using four methodologies. Atmos. Chem. Phys. 2014, 14 (14), 7431-7443.

(73) Dahm, M. M.; Evans, D. E.; Schubauer-Berigan, M. K.; Birch, M. E.; Deddens, J. A. Occupational Exposure Assessment in Carbon Nanotube and Nanofiber Primary and Secondary Manufacturers: Mobile Direct-Reading Sampling. Ann. Occup. Hyg. 2013, 57 (3), 328344.

(74) Dahm, M. M.; Schubauer-Berigan, M. K.; Evans, D. E.; Birch, M. E.; Fernback, J. E.; Deddens, J. A. Carbon Nanotube and Nanofiber Exposure Assessments: An Analysis of 14 Site Visits. Ann. Occup. Hyg. 2015, 59 (6), 705-723.

(75) Vo, E.; Zhuang, Z. Q.; Birch, E.; Zhao, Q.; Horvatin, M.; Liu, Y. W. Measurement of Mass-Based Carbon Nanotube Penetration through Filtering Facepiece Respirator Filtering Media. Ann. Occup. Hyg. 2014, 58 (5), 646-656.

(76) Hashimoto, N.; Ogura, I.; Kotake, M.; Kishimoto, A.; Honda, $\mathrm{K}$., Evaluating the capabilities of portable black carbon monitors and photometers for measuring airborne carbon nanotubes. J. Nanopart. Res. 2013, 15, (11), Article Number: UNSP 2033.

(77) Zhang, L. W.; Petersen, E. J.; Habteselassie, M. Y.; Mao, L.; Huang, Q. G. Degradation of multiwall carbon nanotubes by bacteria. Environ. Pollut. 2013, 181, 335-339.

(78) Flores-Cervantes, D. X.; Maes, H. M.; Schaffer, A.; Hollender, J.; Kohler, H. P. Slow biotransformation of carbon nanotubes by horseradish peroxidase. Environ. Sci. Technol. 2014, 48 (9), 4826-34.

(79) Andon, F. T.; Kapralov, A. A.; Yanamala, N.; Feng, W. H.; Baygan, A.; Chambers, B. J.; Hultenby, K.; Ye, F.; Toprak, M. S.; Brandner, B. D.; Fornara, A.; Klein-Seetharaman, J.; Kotchey, G. P.; Star, A.; Shvedova, A. A.; Fadeel, B.; Kagan, V. E. Biodegradation of Single-Walled Carbon Nanotubes by Eosinophil Peroxidase. Small 2013, 9 (16), 2721-2729.

(80) Farrera, C.; Bhattacharya, K.; Lazzaretto, B.; Andon, F. T.; Hultenby, K.; Kotchey, G. P.; Star, A.; Fadeel, B. Extracellular entrapment and degradation of single-walled carbon nanotubes. Nanoscale 2014, 6 (12), 6974-6983.

(81) Kagan, V. E.; Kapralov, A. A.; St Croix, C. M.; Watkins, S. C.; Kisin, E. R.; Kotchey, G. P.; Balasubramanian, K.; Vlasova, II; Yu, J.; Kim, K.; Seo, W.; MallampaIli, R. K.; Star, A.; Shvedova, A. A. Lung Macrophages "Digest" Carbon Nanotubes Using a Superoxide/ Peroxynitrite Oxidative Pathway. ACS Nano 2014, 8 (6), 5610-5621.

(82) Kotchey, G. P.; Hasan, S. A.; Kapralov, A. A.; Ha, S. H.; Kim, K.; Shvedova, A. A.; Kagan, V. E.; Star, A. A Natural Vanishing Act: The Enzyme-Catalyzed Degradation of Carbon Nanomaterials. Acc. Chem. Res. 2012, 45 (10), 1770-1781.

(83) Kotchey, G. P.; Zhao, Y.; Kagan, V. E.; Star, A. Peroxidasemediated biodegradation of carbon nanotubes in vitro and in vivo. $A d v$. Drug Delivery Rev. 2013, 65 (15), 1921-1932.

(84) Gottschalk, F.; Sonderer, T.; Scholz, R. W.; Nowack, B. Modeled environmental concentrations of engineered nanomaterials
$\left(\mathrm{TiO}_{2}, \mathrm{ZnO}, \mathrm{Ag}, \mathrm{CNT}\right.$, Fullerenes) for different regions. Environ. Sci. Technol. 2009, 43 (24), 9216-9222.

(85) Mueller, N. C.; Nowack, B. Exposure modeling of engineered nanoparticles in the environment. Environ. Sci. Technol. 2008, 42 (12), $4447-4453$

(86) Sun, T. Y.; Conroy, G.; Donner, E.; Hungerbuhler, K.; Lombi, E.; Nowack, B. Probabilistic modelling of engineered nanomaterial emissions to the environment: a spatio-temporal approach. Environ. Sci.: Nano 2015, 2 (4), 340-351.

(87) Montano, M. D.; Badiei, H. R.; Bazargan, S.; Ranville, J. F. Improvements in the detection and characterization of engineered nanoparticles using spICP-MS with microsecond dwell times. Environ. Sci.: Nano 2014, 1 (4), 338-346.

(88) Borovinskaya, O.; Hattendorf, B.; Tanner, M.; Gschwind, S.; Gunther, D. A prototype of a new inductively coupled plasma time-offlight mass spectrometer providing temporally resolved, multi-element detection of short signals generated by single particles and droplets. J. Anal. At. Spectrom. 2013, 28 (2), 226-233.

(89) Borovinskaya, O.; Gschwind, S.; Hattendorf, B.; Tanner, M.; Gunther, D. Simultaneous Mass Quantification of Nanoparticles of Different Composition in a Mixture by Microdroplet GeneratorICPTOFMS. Anal. Chem. 2014, 86 (16), 8142-8148.

(90) Zhu, Y.; Ran, T. C.; Li, Y. G.; Guo, J. X.; Li, W. X. Dependence of the cytotoxicity of multi-walled carbon nanotubes on the culture medium. Nanotechnology 2006, 17 (18), 4668-4674.

(91) Guo, X.; Dong, S.; Petersen, E. J.; Gao, S.; Huang, Q.; Mao, L. Biological Uptake and Depuration of Radio-labeled Graphene by Daphnia magna. Environ. Sci. Technol. 2013, 47 (21), 12524-12531.

(92) Li, D.; Fortner, J. D.; Johnson, D. R.; Chen, C.; Li, Q. L.; Alvarez, P. J. J. Bioaccumulation of ${ }^{14} \mathrm{C}_{60}$ by the Earthworm Eisenia fetida. Environ. Sci. Technol. 2010, 44 (23), 9170-9175.

(93) Liu, J. H.; Yang, S. T.; Wang, X.; Wang, H. F.; Liu, Y. M.; Luo, P. J. G.; Liu, Y. F.; Sun, Y. P. Carbon Nanoparticles Trapped in VivoSimilar to Carbon Nanotubes in Time-Dependent Biodistribution. ACS Appl. Mater. Interfaces 2014, 6 (16), 14672-14678.

(94) Feng, Y. P.; Lu, K.; Mao, L.; Guo, X. K.; Gao, S. X.; Petersen, E. J. Degradation of C-14-labeled few layer graphene via Fenton reaction: Reaction rates, characterization of reaction products, and potential ecological effects. Water Res. 2015, 84, 49-57.

(95) Mao, L.; Hu, M.; Pan, B.; Xie, Y.; Petersen, E. J. Biodistribution and toxicity of radio-labeled few layer graphene in mice after intratracheal instillation. Part. Fibre Toxicol. 2015, 13 (1), 1-12.

(96) Wang, H. F.; Wang, J.; Deng, X. Y.; Sun, H. F.; Shi, Z. J.; Gu, Z. N.; Liu, Y. F.; Zhao, Y. L. Biodistribution of carbon single-wall carbon nanotubes in mice. J. Nanosci. Nanotechnol. 2004, 4 (8), 1019-1024.

(97) Wang, H. F.; Yang, S. T.; Cao, A. N.; Liu, Y. F. Quantification of Carbon Nanomaterials in Vivo. Acc. Chem. Res. 2013, 46 (3), 750760.

(98) Singh, R.; Pantarotto, D.; Lacerda, L.; Pastorin, G.; Klumpp, C.; Prato, M.; Bianco, A.; Kostarelos, K. Tissue biodistribution and blood clearance rates of intravenously administered carbon nanotube radiotracers. Proc. Natl. Acad. Sci. U. S. A. 2006, 103 (9), 3357-3362.

(99) Zhang, L. W.; Petersen, E. J.; Zhang, W.; Chen, Y. S.; Cabrera, M.; Huang, Q. G. Interactions of C-14-labeled multi-walled carbon nanotubes with soil minerals in water. Environ. Pollut. 2012, 166, 7581.

(100) Zhao, Q.; Petersen, E. J.; Cornelis, G.; Wang, X.; Guo, X.; Tao, S.; Xing, B. Retention of 14C-labeled multiwall carbon nanotubes by humic acid and polymers: Roles of macromolecule properties. Carbon 2016, 99, 229-237.

(101) Zhang, D.; Pan, B.; Cook, R. L.; Xing, B. S. Multi-walled carbon nanotube dispersion by the adsorbed humic acids with different chemical structures. Environ. Pollut. 2015, 196, 292-299.

(102) Hyung, H.; Kim, J. H. Natural organic matter (NOM) adsorption to multi-walled carbon nanotubes: Effect of NOM characteristics and water quality parameters. Environ. Sci. Technol. 2008, 42 (12), 4416-4421.

(103) Parks, A. N.; Chandler, G. T.; Ho, K. T.; Burgess, R. M.; Ferguson, P. L. Environmental biodegradability of $\left[\mathrm{C}^{14}\right]$ single-walled 
carbon nanotubes by Trametes versicolor and natural microbial cultures found in New Bedford Harbor sediment and aerated wastewater treatment plant sludge. Environ. Toxicol. Chem. 2015, 34 (2), 247-251.

(104) Bitter, J. L.; Yang, J.; Beigzadeh Milani, S.; Jafvert, C. T.; Fairbrother, D. H. Transformations of oxidized multiwalled carbon nanotubes exposed to UVC $(254 \mathrm{~nm})$ irradiation. Environ. Sci.: Nano 2014, 1 (4), 324-337.

(105) Hou, W.-C.; BeigzadehMilani, S.; Jafvert, C. T.; Zepp, R. G. Photoreactivity of Unfunctionalized Single-Wall Carbon Nanotubes Involving Hydroxyl Radical: Chiral Dependency and Surface Coating Effect. Environ. Sci. Technol. 2014, 48 (7), 3875-3882.

(106) Hou, W. C.; BeigzadehMilani, S.; Jafvert, C. T.; Zepp, R. G. Photoreactivity of Unfunctionalized Single-Wall Carbon Nanotubes Involving Hydroxyl Radical: Chiral Dependency and Surface Coating Effect. Environ. Sci. Technol. 2014, 48 (7), 3875-3882.

(107) Bitter, J. L.; Yang, J.; Milani, S. B.; Jafvert, C. T.; Fairbrother, D. H. Transformations of oxidized multiwalled carbon nanotubes exposed to UVC (254 nm) irradiation. Environ. Sci.: Nano 2014, 1 (4), 324-337.

(108) Chen, C. Y.; Jafvert, C. T. Photoreactivity of Carboxylated Single-Walled Carbon Nanotubes in Sunlight: Reactive Oxygen Species Production in Water. Environ. Sci. Technol. 2010, 44 (17), 6674-6679.

(109) Khripin, C. Y.; Tu, X.; Heddleston, J. M.; Silvera-Batista, C.; Hight Walker, A. R.; Fagan, J.; Zheng, M. High-Resolution Length Fractionation of Surfactant-Dispersed Carbon Nanotubes. Anal. Chem. 2013, 85 (3), 1382-1388.

(110) Hull, M.; Kennedy, A. J.; Detzel, C.; Vikesland, P.; Chappell, M. A. Moving beyond Mass: The Unmet Need to Consider Dose Metrics in Environmental Nanotoxicology Studies. Environ. Sci. Technol. 2012, 46 (20), 10881-10882.

(111) Roebben, G.; Rasmussen, K.; Kestens, V.; Linsinger, T. P. J.; Rauscher, H.; Emons, H.; Stamm, H., Reference materials and representative test materials: the nanotechnology case. J. Nanopart. Res. 2013, 15, (3), Article Number: 1455.

(112) ISO (International Organization for Standardization). TS 10798: Nanotechnologies-charaterization of Single-Wall Carbon Nanotubes Using Scanning Electron Microscopy and Energy Dispersive X-ray Spectrometry Analysis; Geneva, Switzerland, 2011.

(113) ISO (International Organization for Standardization). TS 10867: Nanotechnologies-characterization of Single-Wall Carbon Nanotubes Using near Infrared Photoluminescence Spectroscopy; Geneva, Switzerland, 2010.

(114) ISO (International Organization for Standardization). TS 10868: Nanotechnologies-Characterization of Single-Wall Carbon Nanotubes Using Ultraviolet-Visible-near Infrared (UV-Vis-NIR) Absorption Spectroscopy; Geneva, Switzerland, 2011.

(115) ISO (International Organization for Standardization). TS 10929: Nanotechnologies-characterization of Multiwall Carbon Nanotube (MWCNT) Samples; Geneva, Switzerland, 2012.

(116) ISO (International Organization for Standardization). TS 11251: Characterization of Volatile Components in Single-Wall Carbon Nanotube Samples Using Evolved Gas Analysis/Gas ChromatographMass Spectrometry; Geneva, Switzerland, 2010.

(117) ISO (International Organization for Standardization). TS 11888: Nanotechnologies-Characterization of Multiwall Carbon Nanotubes-Mesoscopic Shape Factors; Geneva, Switzerland, 2011.

(118) ISO (International Organization for Standardization). TS 13278: Nanotechnologies -- Determination of Elemental Impurities in Samples of Carbon Nanotubes Using Inductively Coupled Plasma Mass Spectrometry; Geneva, Switzerland, 2011.

(119) Organization for Economic Cooperation and Development. Bioaccumulation in fish: Aqueous and Dietary Exposure, OECD Guideline 305. Paris, France, 2012.

(120) Edgington, A. J.; Roberts, A. P.; Taylor, L. M.; Alloy, M. M.; Reppert, J.; Rao, A. M.; Ma, J. D.; Klaine, S. J. The influence of natural organic matter on the toxicity of multiwalled carbon nanotubes. Environ. Toxicol. Chem. 2010, 29 (11), 2511-2518.
(121) Leeuw, T. K.; Reith, R. M.; Simonette, R. A.; Harden, M. E.; Cherukuri, P.; Tsyboulski, D. A.; Beckingham, K. M.; Weisman, R. B. Single-walled carbon nanotubes in the intact organism: Near-IR imaging and biocompatibility studies in Drosophila. Nano Lett. 2007, 7 (9), 2650-2654.

(122) Mouchet, F.; Landois, P.; Puech, P.; Pinelli, E.; Flahaut, E.; Gauthier, L. Carbon nanotube ecotoxicity in amphibians: assessment of multiwalled carbon nanotubes and comparison with double-walled carbon nanotubes. Nanomedicine 2010, 5 (6), 963-974.

(123) Mouchet, F.; Landois, P.; Sarremejean, E.; Bernard, G.; Puech, P.; Pinelli, E.; Flahaut, E.; Gauthier, L. Characterisation and in vivo ecotoxicity evaluation of double-wall carbon nanotubes in larvae of the amphibian Xenopus laevis. Aquat. Toxicol. 2008, 87 (2), 127-137.

(124) Maes, H. M.; Stibany, F.; Giefers, S.; Daniels, B.; Deutschmann, B.; Baumgartner, W.; Schaffer, A. Accumulation and Distribution of Multiwalled Carbon Nanotubes in Zebrafish (Danio rerio). Environ. Sci. Technol. 2014, 48 (20), 12256-12264.

(125) Li, S. B.; Irin, F.; Atore, F. O.; Green, M. J.; Canas-Carrell, J. E. Determination of multi-walled carbon nanotube bioaccumulation in earthworms measured by a microwave-based detection technique. Sci. Total Environ. 2013, 445, 9-13.

(126) Rösslein, M.; Elliott, J. T.; Salit, M. L.; Petersen, E. J.; Hirsch, C.; Krug, H. F.; Wick, P. The use of cause-and-effect analysis to design a high quality nano-cytotoxicology assay. Chem. Res. Toxicol. 2014, 27 (10), 1877-1884.

(127) Hammes, K.; Schmidt, M. W. I.; Smernik, R. J.; Currie, L. A.; Ball, W. P.; Nguyen, T. H.; Louchouarn, P.; Houel, S.; Gustafsson, Ö.; Elmquist, M.; Cornelissen, G.; Skjemstad, J. O.; Masiello, C. A.; Song, J.; Peng, P. a.; Mitra, S.; Dunn, J. C.; Hatcher, P. G.; Hockaday, W. C.; Smith, D. M.; Hartkopf-Fröder, C.; Böhmer, A.; Lüer, B.; Huebert, B. J.; Amelung, W.; Brodowski, S.; Huang, L.; Zhang, W.; Gschwend, P. M.; Flores-Cervantes, D. X.; Largeau, C.; Rouzaud, J.-N.; Rumpel, C.; Guggenberger, G.; Kaiser, K.; Rodionov, A.; Gonzalez-Vila, F. J.; Gonzalez-Perez, J. A.; de la Rosa, J. M.; Manning, D. A. C.; LópezCapél, E.; Ding, L., Comparison of quantification methods to measure fire-derived (black/elemental) carbon in soils and sediments using reference materials from soil, water, sediment and the atmosphere. Global Biogeochem. Cycles 2007, 21, (3), Article Number: GB3016.10.1029/2006GB002914

(128) Cleveland, D.; Long, S. E.; Pennington, P. L.; Cooper, E.; Fulton, M. H.; Scott, G. I.; Brewer, T.; Davis, J.; Petersen, E. J.; Wood, L. Pilot estuarine mesocosm study on the environmental fate of silver nanomaterials leached from consumer products. Sci. Total Environ. 2012, 421, 267-272.

(129) Bour, A.; Mouchet, F.; Silvestre, J.; Gauthier, L.; Pinelli, E. Environmentally relevant approaches to assess nanoparticles ecotoxicity: A review. J. Hazard. Mater. 2015, 283, 764-777.

(130) Chen, B. L.; Selegue, J. P. Separation and characterization of single-walled and multiwalled carbon nanotubes by using flow fieldflow fractionation. Anal. Chem. 2002, 74 (18), 4774-4780.

(131) Moon, M. H.; Kang, D. J.; Jung, J. H.; Kim, J. M. Separation of carbon nanotubes by frit inlet asymmetrical flow field-flow fractionation. J. Sep. Sci. 2004, 27 (9), 710-717.

(132) Chun, J.; Fagan, J. A.; Hobbie, E. K.; Bauer, B. J. Size separation of single-wall carbon nanotubes by flow-field flow fractionation. Anal. Chem. 2008, 80 (7), 2514-2523.

(133) Gigault, J.; Grassl, B.; Lespes, G. Size characterization of the associations between carbon nanotubes and humic acids in aqueous media by asymmetrical flow field-flow fractionation combined with multi-angle light scattering. Chemosphere 2012, 86 (2), 177-182.

(134) Doorn, S. K.; Fields, R. E.; Hu, H.; Hamon, M. A.; Haddon, R. C.; Selegue, J. P.; Majidi, V. High resolution capillary electrophoresis of carbon nanotubes. J. Am. Chem. Soc. 2002, 124 (12), 3169-3174.

(135) Doorn, S. K.; Strano, M. S.; O’Connell, M. J.; Haroz, E. H.; Rialon, K. L.; Hauge, R. H.; Smalley, R. E. Capillary electrophoresis separations of bundled and individual carbon nanotubes. J. Phys. Chem. B 2003, 107 (25), 6063-6069. 
(136) Suarez, B.; Simonet, B. M.; Cardenas, S.; Valcarcel, M. Separation of carbon nanotubes in aqueous medium by capillary electrophoresis. J. Chromat. A 2006, 1128 (1-2), 282-289.

(137) Lopez-Pastor, M.; Dominguez-Vidal, A.; Ayora-Canada, M. J.; Simonet, B. M.; Lendl, B.; Valcarcel, M. Separation of single-walled carbon nanotubes by use of ionic liquid-aided capillary electrophoresis. Anal. Chem. 2008, 80 (8), 2672-2679.

(138) Fagan, J. A.; Becker, M. L.; Chun, J. H.; Nie, P. T.; Bauer, B. J.; Simpson, J. R.; Hight-Walker, A.; Hobbie, E. K. Centrifugal length separation of carbon nanotubes. Langmuir 2008, 24 (24), 1388013889.

(139) Komatsu, N.; Wang, F. A Comprehensive Review on Separation Methods and Techniques for Single-Walled Carbon Nanotubes. Materials 2010, 3 (7), 3818-3844.

(140) Fagan, J. A.; Becker, M. L.; Chun, J.; Hobbie, E. K. Length fractionation of carbon nanotubes using centrifugation. Adv. Mater. 2008, 20 (9), 1609-1613.

(141) Duesberg, G. S.; Blau, W.; Byrne, H. J.; Muster, J.; Burghard, M.; Roth, S. Chromatography of carbon nanotubes. Synth. Met. 1999, 103 (1-3), 2484-2485.

(142) Duesberg, G. S.; Burghard, M.; Muster, J.; Philipp, G.; Roth, S. Separation of carbon nanotubes by size exclusion chromatography. Chem. Commun. 1998, 3, 435-436.

(143) Duesberg, G. S.; Muster, J.; Krstic, V.; Burghard, M.; Roth, S. Chromatographic size separation of single-wall carbon nanotubes. Appl. Phys. A: Mater. Sci. Process. 1998, 67 (1), 117-119.

(144) Farkas, E.; Anderson, M. E.; Chen, Z. H.; Rinzler, A. G. Length sorting cut single wall carbon nanotubes by high performance liquid chromatography. Chem. Phys. Lett. 2002, 363 (1-2), 111-116.

(145) Zhao, B.; Hu, H.; Niyogi, S.; Itkis, M. E.; Hamon, M. A.; Bhowmik, P.; Meier, M. S.; Haddon, R. C. Chromatographic Purification and Properties of Soluble Single-Walled Carbon Nanotubes. J. Am. Chem. Soc. 2001, 123 (47), 11673-11677.

(146) Ziegler, K. J.; Schmidt, D. J.; Rauwald, U.; Shah, K. N.; Flor, E. L.; Hauge, R. H.; Smalley, R. E. Length-dependent extraction of singlewalled carbon nanotubes. Nano Lett. 2005, 5 (12), 2355-2359.

(147) Flavel, B. S.; Moore, K. E.; Pfohl, M.; Kappes, M. M.; Hennrich, F. Separation of Single-Walled Carbon Nanotubes with a Gel Permeation Chromatography System. ACS Nano 2014, 8 (2), $1817-1826$

(148) Suarez, B.; Moliner-Martinez, Y.; Cardenas, S.; Simonet, B. M.; Valcarcel, M. Monitoring of carboxylic carbon nanotubes in surface water by using multiwalled carbon nanotube-modified filter as preconcentration unit. Environ. Sci. Technol. 2008, 42 (16), 61006104.

(149) Ziolkowski, L. A.; Druffel, E. R. M. The feasibility of isolation and detection of fullerenes and carbon nanotubes using the benzene polycarboxylic acid method. Mar. Pollut. Bull. 2009, 59 (4-7), 213218.

(150) Mattison, N. T.; O'Carroll, D. M.; Rowe, R. K.; Petersen, E. J. Impact of Porous Media Grain Size on the Transport of Multi-walled Carbon Nanotubes. Environ. Sci. Technol. 2011, 45 (22), 9765-9775. (151) O'Carroll, D. M.; Liu, X.; Mattison, N. T.; Petersen, E. J. Impact of diameter on carbon nanotube transport in sand. J. Colloid Interface Sci. 2013, 390, 96-104.

(152) Parks, A. N.; Portis, L. M.; Schierz, P. A.; Washburn, K. M.; Perron, M. M.; Burgess, R. M.; Ho, K. T.; Chandler, G. T.; Ferguson, P. L. Bioaccumulation and toxicity of single-walled carbon nanotubes to benthic organisms at the base of the marine food chain. Environ. Toxicol. Chem. 2013, 32 (6), 1270-1277.

(153) Hennrich, F.; Krupke, R.; Lebedkin, S.; Arnold, K.; Fischer, R.; Resasco, D. E.; Kappes, M. Raman spectroscopy of individual singlewalled carbon nanotubes from various sources. J. Phys. Chem. B 2005, 109 (21), 10567-10573.

(154) Heeg, S.; Malic, E.; Casiraghi, C.; Reich, S. Quantitative composition of a single-walled carbon nanotube sample: Raman scattering versus photoluminescence. Phys. Status Solidi B 2009, 246 (11-12), 2740-2743.
(155) Dresselhaus, M. S.; Jorio, A.; Hofmann, M.; Dresselhaus, G.; Saito, R. Perspectives on Carbon Nanotubes and Graphene Raman Spectroscopy. Nano Lett. 2010, 10 (3), 751-758.

(156) Caballero-Diaz, E.; Guzman-Ruiz, R.; Malagon, M. M.; Simonet, B. M.; Valcarcel, M. Effects of the interaction of singlewalled carbon nanotubes with 4-nonylphenol on their in vitro toxicity. J. Hazard. Mater. 2014, 275, 107-115.

(157) Lopez-Lorente, A. I.; Simonet, B. M.; Valcarcel, M. Raman spectroscopic characterization of single walled carbon nanotubes: influence of the sample aggregation state. Analyst 2014, 139 (1), 290298.

(158) Lopez-Lorente, A. I.; Simonet, B. M.; Valcarcel, M.; Mizaikoff, B. Bare gold nanoparticles mediated surface-enhanced Raman spectroscopic determination and quantification of carboxylated single-walled carbon nanotubes. Anal. Chim. Acta 2013, 788, 122-128.

(159) Lopez-Lorente, A. I.; Simonet, B. M.; Valcarcel, M. Qualitative detection and quantitative determination of single-walled carbon nanotubes in mixtures of carbon nanotubes with a portable Raman spectrometer. Analyst 2013, 138 (8), 2378-2385.

(160) Marches, R.; Mikoryak, C.; Wang, R. H.; Pantano, P.; Draper, R. K.; Vitetta, E. S. The importance of cellular internalization of antibody-targeted carbon nanotubes in the photothermal ablation of breast cancer cells. Nanotechnology 2011, 22, (9), Article Number: 095101.

(161) Liu, Z.; Davis, C.; Cai, W. B.; He, L.; Chen, X. Y.; Dai, H. J. Circulation and long-term fate of functionalized, biocompatible singlewalled carbon nanotubes in mice probed by Raman spectroscopy. Proc. Natl. Acad. Sci. U. S. A. 2008, 105 (5), 1410-1415.

(162) Salzmann, C. G.; Chu, B. T. T.; Tobias, G.; Llewellyn, S. A.; Green, M. L. H. Quantitative assessment of carbon nanotube dispersions by Raman spectroscopy. Carbon 2007, 45 (5), 907-912.

(163) Athalin, H.; Lefrant, S. L. A correlated method for quantifying mixed and dispersed carbon nanotubes: analysis of the Raman band intensities and evidence of wavenumber shift. J. Raman Spectrosc. 2005, 36 (5), 400-408

(164) Nunes, A.; Bussy, C.; Gherardini, L.; Meneghetti, M.; Herrero, M. A.; Bianco, A.; Prato, M.; Pizzorusso, T.; Al-Jamal, K. T.; Kostarelos, K. In vivo degradation of functionalized carbon nanotubes after stereotactic administration in the brain cortex. Nanomedicine 2012, 7 (10), 1485-1494.

(165) Batista, C. A. S.; Zheng, M.; Khripin, C. Y.; Tu, X. M.; Fagan, J. A. Rod Hydrodynamics and Length Distributions of Single-Wall Carbon Nanotubes Using Analytical Ultracentrifugation. Langmuir 2014, 30 (17), 4895-4904.

(166) Badireddy, A. R.; Wiesner, M. R.; Liu, J. Detection, Characterization, and Abundance of Engineered Nanoparticles in Complex Waters by Hyperspectral Imagery with Enhanced Darkfield Microscopy. Environ. Sci. Technol. 2012, 46 (18), 10081-10088.

(167) Mortimer, M.; Gogos, A.; Bartolome, N.; Kahru, A.; Bucheli, T. D.; Slaveykova, V. I. Potential of Hyperspectral Imaging Microscopy for Semi-quantitative Analysis of Nanoparticle Uptake by Protozoa. Environ. Sci. Technol. 2014, 48 (15), 8760-8767.

(168) Berciaud, S.; Cognet, L.; Poulin, P.; Weisman, R. B.; Lounis, B. Absorption spectroscopy of individual single-walled carbon nanotubes. Nano Lett. 2007, 7 (5), 1203-1207.

(169) Nedosekin, D. A.; Shashkov, E. V.; Galanzha, E. I.; Hennings, L.; Zharov, V. P. Photothermal Multispectral Image Cytometry for Quantitative Histology of Nanoparticles and Micrometastasis in Intact, Stained and Selectively Burned Tissues. Cytometry, Part A 2010, 77A (11), 1049-1058.

(170) Hong, H.; Chen, F.; Cai, W. B. Pharmacokinetic Issues of Imaging with Nanoparticles: Focusing on Carbon Nanotubes and Quantum Dots. Mol. Imag. Biol. 2013, 15 (5), 507-520.

(171) Lehman, J. H.; Terrones, M.; Mansfield, E.; Hurst, K. E.; Meunier, V. Evaluating the characteristics of multiwall carbon nanotubes. Carbon 2011, 49 (8), 2581-2602.

(172) Mansfield, E.; Kar, A.; Wang, C. M.; Chiaramonti, A. N. Statistical sampling of carbon nanotube populations by thermogravimetric analysis. Anal. Bioanal. Chem. 2013, 405 (25), 8207-8213. 
(173) Petersen, E. J.; Huang, Q.; Weber, W. J., Jr. Bioaccumulation of radio-labeled carbon nanotubes by Eisenia foetida. Environ. Sci. Technol. 2008, 42 (8), 3090-3095.

(174) Petersen, E. J.; Huang, Q.; Weber, W. J., Jr. Ecological uptake and depuration of carbon nanotubes by Lumbriculus variegatus. Environ. Health Perspect. 2008, 116 (4), 496-500.

(175) Petersen, E. J.; Pinto, R. A.; Zhang, L.; Huang, Q. G.; Landrum, P. F.; Weber, W. J. Effects of polyethyleneimine-mediated functionalization of multi-walled carbon nanotubes on earthworm bioaccumulation and sorption by soils. Environ. Sci. Technol. 2011, 45 (8), 37183724.

(176) Zhang, L.; Petersen, E. J.; Qingguo, H. Phase Distribution of 14C-Labeled Multiwalled Carbon Nanotubes in Aqueous Systems Containing Model Solids: Peat. Environ. Sci. Technol. 2011, 45 (4), 1356-1362.

(177) Petersen, E. J.; Akkanen, J.; Kukkonen, J. V. K.; Weber, W. J., Jr. Biological Uptake and Depuration of Carbon Nano-tubes by Daphnia magna. Environ. Sci. Technol. 2009, 43 (8), 2969-2975.

(178) Petersen, E. J.; Huang, Q. G.; Weber, W. J., Jr. Relevance of octanol-water distribution measurements to the potential ecological uptake of multi-walled carbon nanotubes. Environ. Toxicol. Chem. 2010, 29 (5), 1106-1112.

(179) Larue, C.; Pinault, M.; Czarny, B.; Georgin, D.; Jaillard, D.; Bendiab, N.; Mayne-L'Hermite, M.; Taran, F.; Dive, V.; Carriere, M. Quantitative evaluation of multi-walled carbon nanotube uptake in wheat and rapeseed. J. Hazard. Mater. 2012, 227, 155-163.

(180) Zhang, L.; Petersen, E. J.; Habteselassie, M. Y.; Mao, L.; Huang, Q. Degradation of multiwall carbon nanotubes by bacteria. Environ. Pollut. 2013, 181, 335-339.

(181) Rhiem, S.; Riding, M. J.; Baumgartner, W.; Martin, F. L.; Semple, K. T.; Jones, K. C.; Schaffer, A.; Maes, H. M. Interactions of multiwalled carbon nanotubes with algal cells: Quantification of association, visualization of uptake, and measurement of alterations in the composition of cells. Environ. Pollut. 2015, 196, 431-439.

(182) Fagan, J. A.; Zheng, M.; Rastogi, V.; Simpson, J. R.; Khripin, C. Y.; Batista, C. A. S.; Walker, A. R. H. Analyzing Surfactant Structures on Length and Chirality Resolved $(6,5)$ Single-Wall Carbon Nanotubes by Analytical Ultracentrifugation. ACS Nano 2013, 7 (4), 3373-3387.

(183) Arnold, M. S.; Suntivich, J.; Stupp, S. I.; Hersam, M. C. Hydrodynamic Characterization of Surfactant Encapsulated Carbon Nanotubes Using an Analytical Ultracentrifuge. ACS Nano 2008, 2 (11), 2291-2300.

(184) Backes, C.; Karabudak, E.; Schmidt, C. D.; Hauke, F.; Hirsch, A.; Wohlleben, W. Determination of the Surfactant Density on SWCNTs by Analytical Ultracentrifugation. Chem. - Eur. J. 2010, 16 (44), 13176-13184.

(185) Kim, K. T.; Edgington, A. J.; Klaine, S. J.; Cho, J. W.; Kim, S. D. Influence of multiwalled carbon nanotubes dispersed in natural organic matter on speciation and bioavailability of copper. Environ. Sci. Technol. 2009, 43 (23), 8979-8984.

(186) Bourdiol, F.; Dubuc, D.; Grenier, K.; Mouchet, F.; Gauthier, L.; Flahaut, E. Quantitative detection of carbon nanotubes in biological samples by an original method based on microwave permittivity measurements. Carbon 2015, 81, 535-545.

(187) Cano, A.; Kohl, K.; Deleon, S.; Payton, P.; Irin, F.; Saed, M.; Shah, S. A.; Green, M. J.; Cañas-Carrell, J. E. Determination of uptake, accumulation, and stress effects in corn (Zea mays L.) grown in singlewall carbon nanotube contaminated soil. Chemosphere 2016, 152, $117-122$.

(188) Menendez, J. A.; Arenillas, A.; Fidalgo, B.; Fernandez, Y.; Zubizarreta, L.; Calvo, E. G.; Bermudez, J. M. Microwave heating processes involving carbon materials. Fuel Process. Technol. 2010, 91 (1), 1-8.

(189) Garner, K. L.; Suh, S.; Lenihan, H. S.; Keller, A. A. Species Sensitivity Distributions for Engineered Nanomaterials. Environ. Sci. Technol. 2015, 49 (9), 5753-5759. 